\title{
Intake rates and the functional response in shorebirds (Charadriiformes) eating macro-invertebrates
}

John D. Goss-Custard ${ }^{1 *}$, Andrew D. West ${ }^{1}$, Michael G. Yates ${ }^{1}$, Richard W. G. Caldow ${ }^{1}$, Richard A. Stillman ${ }^{1}$, Louise Bardsley ${ }^{1}$, Juan Castilla ${ }^{2}$, Macarena Castro ${ }^{3}$, Volker Dierschke $^{4}$, Sarah E. A. Le V. dit Durell ${ }^{1}$, Goetz Eichhorn ${ }^{5}$, Bruno J. Ens ${ }^{6}$, Klaus-Michael Exo ${ }^{7}$, P. U. Udayangani-Fernando ${ }^{8}$, Peter N. Ferns ${ }^{9}$, Philip A. R. Hockey $^{10}$, Jennifer A. Gill ${ }^{11}$, Ian Johnstone ${ }^{12}$, Bozena Kalejta-Summers ${ }^{13}$, Jose A., Masero $^{3}$, Francisco Moreira ${ }^{14}$, Rajarathina Velu Nagarajan ${ }^{15}$, Ian P. F. Owens ${ }^{16}$, Cristian Pacheco ${ }^{2}$, Alejandro Perez-Hurtado ${ }^{3}$, Danny Rogers ${ }^{17}$, Gregor Scheiffarth ${ }^{7}$, Humphrey Sitters ${ }^{18}$, William J. Sutherland ${ }^{11}$, Patrick Triplet ${ }^{19}$, Dave H. Worrall ${ }^{20}$, Yuri Zharikov $^{21}$, Leo Zwarts ${ }^{22}$ and Richard A. Pettifor ${ }^{23}$

${ }^{1}$ Centre for Ecology and Hydrology, Winfrith Technology Centre, Dorchester DT2 8ZD, UK

${ }^{2}$ Departamento de Ecologia, Facultad de Ciencias Biologicas, Pontificia Universidad Catolica de Chile, Codigo Postal: 6513677, Santiago, Chile

${ }^{3}$ Departamento de Biologia, Facultad de Ciencias del Mar y Ambientals, E-11510 Puerto Real, Spain

${ }^{4}$ Research and Technology Centre, University of Kiel, Hafentörn, D-25671 Büsum, Germany

5 Zoological Laboratory, University of Groningen, PO Box 14, 9750 AA Haren, The Netherlands

${ }^{6}$ Alterra, P.O. Box 167, NL-1790 AD Den Burg (Texel), The Netherlands

${ }^{7}$ Institut für Vogelforschung "Vogelwarte Helgoland", An der Vogelwarte 21, D-26386 Wilhelmshaven, Germany

829 Askam Road, Bramley, Rotherham, South Torkshire S66 3YR, UK

${ }^{9}$ School of Biosciences, Cardiff University, Cardiff CF10 3TL, UK

${ }^{10}$ DST INRF Centre of Excellence at the Percy FitzPatrick Institute of African Ornithology, University of Cape Town,

Rondebosch 7701, South Africa

${ }^{11}$ Schools of Biological and Environmental Sciences, University of East Anglia, Norwich NR4 7 T7, UK

${ }^{12}$ RSPB North Wales Office, Maes y Ffynnon, Penrhosgarnedd, Bangor LL57 2DW, UK

137 Mill Crescent, $\mathcal{N}$. Kessock, Inverness IV1 3XY, UK

${ }^{14}$ Centro de Ecologia Aplicada 'Prof. Baeta Neves', Instituto Superior de Agraonomia, Tapada da Ajuda, 1349-017 Lisboa, Portugal

${ }^{15}$ Department of Psychology, University of Exeter, Exeter EX4 4QG, UK

${ }^{16}$ Department of Biological Sciences, and NERC Centre for Population Biology, Imperial College London, Silwood Park, Ascot, Berkshire SL5 7PY, UK

17 Johnstone Centre, Charles Stuart University, PO Box 789, Albury NSW 2640, Australia

${ }^{18}$ Limosa, Old Ebford Lane, Ebford, Exeter EX3 OQR, UK

19 SMACOPI, 1 place de l'Amiral Courbet, 80100 Abbeville, France

${ }^{20}$ Countryside Council for Wales, Haverfordwest, Pembrokeshire SA67 8TB, UK

${ }^{21}$ SOLS, University of Queensland, Brisbane, OLD 4072, Australia

${ }^{22}$ RIZA, P.O. Box 17, Lelystad, The Netherlands

${ }^{23}$ Institute of Zoology, Zoological Society of London, Regents Park, London NW1 4RY, UK

(Received 1 November 2005; revised 19 May 2006; accepted 22 May 2006)

\footnotetext{
* Author for correspondence: J. D. Goss-Custard, Havering, Church Road, Lympstone, Devon, EX8 5JT, UK. (E-mail: j.d.gosscustard@exeter.ac.uk)

$\dagger$ Present address: PG and Research Department of Zoology and Wildlife Biology, AVC College (Autonomous), Mannampandal-609305, India.
} 


\section{ABSTRACT}

As field determinations take much effort, it would be useful to be able to predict easily the coefficients describing the functional response of free-living predators, the function relating food intake rate to the abundance of food organisms in the environment. As a means easily to parameterise an individual-based model of shorebird Charadriiformes populations, we attempted this for shorebirds eating macro-invertebrates. Intake rate is measured as the ash-free dry mass (AFDM) per second of active foraging; i.e. excluding time spent on digestive pauses and other activities, such as preening. The present and previous studies show that the general shape of the functional response in shorebirds eating approximately the same size of prey across the full range of prey density is a decelerating rise to a plateau, thus approximating the Holling type II ('disc equation') formulation. But field studies confirmed that the asymptote was not set by handling time, as assumed by the disc equation, because only about half the foraging time was spent in successfully or unsuccessfully attacking and handling prey, the rest being devoted to searching.

A review of 30 functional responses showed that intake rate in free-living shorebirds varied independently of prey density over a wide range, with the asymptote being reached at very low prey densities $\left(<150 / \mathrm{m}^{-2}\right)$. Accordingly, most of the many studies of shorebird intake rate have probably been conducted at or near the asymptote of the functional response, suggesting that equations that predict intake rate should also predict the asymptote.

A multivariate analysis of 468 'spot' estimates of intake rates from 26 shorebirds identified ten variables, representing prey and shorebird characteristics, that accounted for $81 \%$ of the variance in logarithm-transformed intake rate. But four-variables accounted for almost as much $(77.3 \%)$, these being bird size, prey size, whether the bird was an oystercatcher Haematopus ostralegus eating mussels Mytilus edulis, or breeding. The four variable equation under-predicted, on average, the observed 30 estimates of the asymptote by $11.6 \%$, but this discrepancy was reduced to $0.2 \%$ when two suspect estimates from one early study in the 1960 s were removed. The equation therefore predicted the observed asymptote very successfully in $93 \%$ of cases.

We conclude that the asymptote can be reliably predicted from just four easily measured variables. Indeed, if the birds are not breeding and are not oystercatchers eating mussels, reliable predictions can be obtained using just two variables, bird and prey sizes. A multivariate analysis of 23 estimates of the half-asymptote constant suggested they were smaller when prey were small but greater when the birds were large, especially in oystercatchers. The resulting equation could be used to predict the half-asymptote constant, but its predictive power has yet to be tested.

As well as predicting the asymptote of the functional response, the equations will enable research workers engaged in many areas of shorebird ecology and behaviour to estimate intake rate without the need for conventional time-consuming field studies, including species for which it has not yet proved possible to measure intake rate in the field.

Key words: Charadriiformes, foraging behaviour, functional response, individual-based models, intake rate, predatorprey interactions, shorebirds.

\section{CONTENTS}

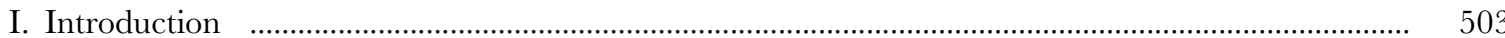

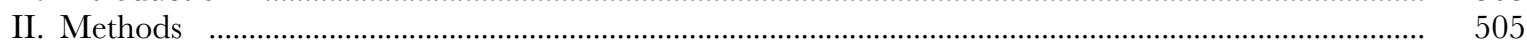

(1) Functional responses ………….......................................................................................... 505

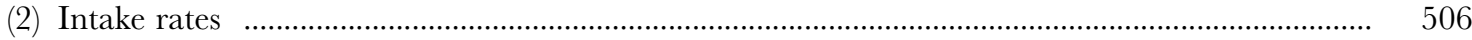

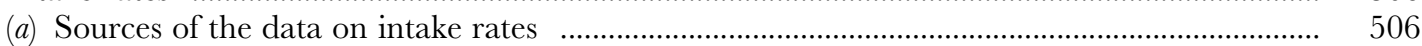

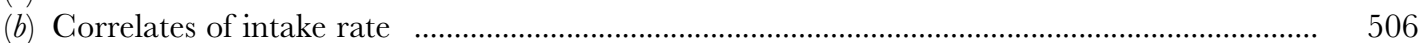

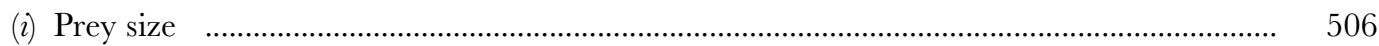

(ii) Bird size ………....................................................................................................... 506

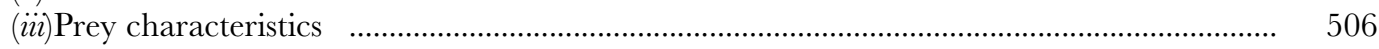

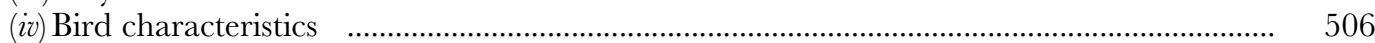

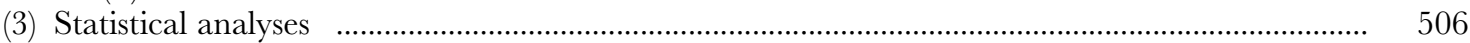

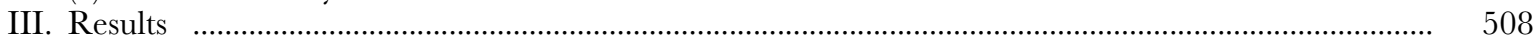

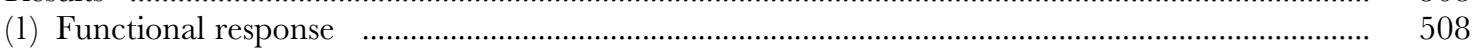

(a) Asymptote and half-asymptote constant ………………....................................................... 508

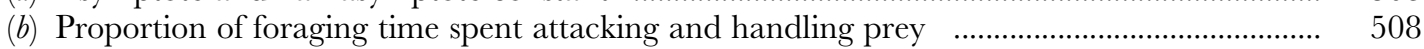

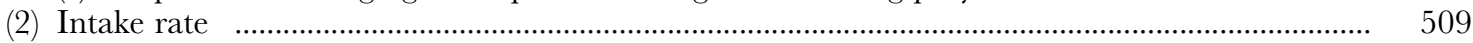


(a) European oystercatchers eating cockles and mussels

(b) Other bird and prey species

(3) Predicting the coefficients of the functional response

(a) Asymptote

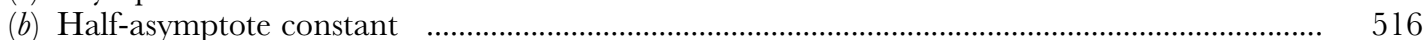

IV. Discussion

(1) Phylogenetic effects

(2) Causal basis of the correlates of intake rate

(3) What determines the asymptote?

(4) Predicting the coefficients of the functional response

(5) Utility of the predictive equations

IX. Appendix 2. Results of adding fixed effects to generalised linear mixed models

\section{INTRODUCTION}

The rate at which a foraging animal consumes its food forms the basis of innumerable studies in ecology. A minimal list of the ecological and behavioural issues for which measuring the intake rate is a fundamental requirement would include studies of energy budgets, predator-prey interactions, foraging theory, the quality of feeding grounds, the trade-off between consuming food and other factors that may affect fitness, such as the risk of being taken by a predator, and food-related reproductive success.

In many studies, it is also necessary to determine how the intake rate changes as the abundance of the food in the environment changes. This relationship is known as the functional response and is most commonly expressed as the relationship between a forager's intake rate and food density. Whatever the precise shape of this relationship in a particular case, two constraints cause the functional responses of vertebrates to have two general characteristics. The first is that when the particular food organism occurs at very low densities relative to the rate at which the animal can search its environment, the intake rate on that food organism is very low because it takes so long to find each food item. The second is that, when the food organism is very abundant and successive prey are found very rapidly, some limitation prevents the further increase in intake rate on that food organism such that a maximum intake rate is reached; for example, the limited rate at which the gut can process food may set a limit to the rate at which food can be consumed over a given time period. In vertebrates, therefore, the functional response takes the form of a function in which intake rate increases from zero when there is no food in the environment up to a maximum that often approximates an asymptote.

The parameters describing this function must be known if we are to model and predict how the intake rate of foragers is affected by food abundance, but they are usually difficult and time-consuming to determine in the field (Bergstrom \& England, 2004). Despite its importance for so many ecological studies, remarkably few functional responses have been described for foragers in the wild (Jeschke, Kopp \& Tollrian, 2004), even in such well-studied animals as birds. The present study was undertaken to try to construct a method by which the parameters of the functional response could be estimated so that they could be used in individual-based models (IBMs) - that are also behaviour-based - of shorebird (Charadriiformes) populations (Goss-Custard \& Stillman, in press). Individual-based models are increasingly being used to solve applied ecological questions to which conventional ecological procedures fail to provide the answers (Grimm \& Railsbeck, 2005). This paper is therefore concerned only with shorebirds in which the intake rate has routinely been measured as the ash-free dry mass (AFDM) or energy consumed per second in birds that are foraging actively for all the time during which they are observed; i.e. time spent on other activities, such as resting, preening etc. is not included in the time-base. Given the very short time-base of this definition of intake rate, it would perhaps be strictly more correct to refer to this measure of food consumption as the 'instantaneous intake rate' to distinguish it clearly from measurements made over much longer periods of a day or more when the balance between energy consumption and expenditure is being considered. However, the convention has arisen in studies of shorebird foraging behaviour and ecology to refer to it simply as 'intake rate', and we follow this convention here.

Another convention that has arisen in studies of shorebird foraging is to distinguish between 'intake rate' and 'feeding rate'. As already discussed, the former term refers to the rate at which prey biomass or energy (or some other component of the food) is consumed in $1 \mathrm{~s}$. By contrast, the term 'feeding rate' refers just to the numbers of prey items consumed over the same time interval. This is an important distinction because, in shorebirds, the mean biomass and energy content of a given prey type (e.g. a ragworm Hediste (=Nereis) diversicolor) can vary enormously between seasons and locations just as - although more widely known - bitesize can vary in herbivorous wildfowl and mammals. 
Whereas in some taxa the biomass of a given prey type is more-or-less constant so that the terms 'feeding rate' and 'intake rate' can be used interchangeably, this is usually not the case in shorebirds. For example, intake rate in Eurasian oystercatchers Haematopus ostralegus eating mussels Mytilus edulis can vary several-fold between birds and seasons even though the feeding rate is more-or-less the same (Goss-Custard et al., 2001).

The intake rate functional responses of free-living shorebirds feeding on macro-invertebrates, usually in the intertidal zone but sometimes in fields, follows the general form of the Holling (1959) type II ('disc equation') theoretical model of a decelerating rise in intake rate to an asymptote (Goss-Custard, 1977 b,d; Hulscher, 1982; Sutherland, $1982 a, b$; Barnard \& Thompson, 1985; Ens et al., $1996 c$; Norris \& Johnstone, $1998 b$; Gill, Norris \& Sutherland, 2001; Goss-Custard et al., 2001; Hiddink, 2003; Smart \& Gill, 2003) or, sometimes, type IV, in which intake declines somewhat at very high prey densities (Goss-Custard, $1977 b, d$ ). In this formulation, the maximum or asymptotic intake rate is determined by how long it takes the forager to capture and swallow one prey item, the duration of this period being known as the 'handling time'. At the asymptote of the functional response, the prey items are so abundant that the forager finds another prey immediately after it has swallowed the preceding one. Thus, the maximum number of prey items consumed per unit time while actively foraging (the 'feeding rate') is the reciprocal of the handling time; at the asymptote, all the foraging time is taken up in handling prey. The asymptotic intake rate is, of course, the product of the asymptotic feeding rate and the food value of the average prey item, whether this is measured in terms of its biomass, energy content or nutrient content.

But despite this apparent convergence in shorebirds between theoretical expectations and empirical evidence, an increasing number of studies suggest that the assumptions of the disc equation often do not hold in shorebirds, or in other groups of birds or in predators in general (Mitchell \& Brown, 1990; Caldow \& Furness, 2001; Jeschke, Kopp \& Tollrian, 2002; Whelan \& Brown, 2005). Despite the attractive simplicity and very widespread application of the disc equation, the evidence has gradually accumulated that, over a short time-base, the maximum number of prey consumed per unit time is not the reciprocal of time spent attacking and handling prey. Early studies on shorebirds (Wanink \& Zwarts, 1985) and passerines (Green, 1978) provided the first indications that this was the case by showing that the asymptote occurred well below the level at which all the time was spent attacking - either successfully or unsuccessfully - and handling prey. At the asymptote, shorebirds were spending significant amounts of time searching for prey.

A number of ideas have been invoked to explain why the asymptotic intake rate may occur below the level set by handling time. Hulscher (1982), Krebs, Stephens \& Sutherland (1983) and Wanink \& Zwarts (1985) propose that birds become more selective as prey density increases and so consume an increasingly narrow range of prey types, causing the number of prey consumed per unit time to decelerate. However, if the birds do select increasingly profitable prey types, their intake rate could still continue to increase until all the time is spent attacking and handling the most profitable prey. This would also be expected to happen if birds selected prey for reasons other than maximising profitability, such as minimising the risk of infection by parasites: eventually the density of low-risk prey would be high enough for the birds to spend all their time attacking and consuming the currently most desirable prey alone.

The limited capacity and rate at which the gut can process food could, in principle, limit intake rate and set the asymptote below that which would be determined by handling time alone (Jeschke et al., 2002; Jeschke \& Tollrian, 2005; Whelan \& Brown, 2005). This possibility is difficult to test in the field because both gut capacity and processing rate vary, largely according to the energetic requirements of the animal (Jeschke et al., 2002). However, the asymptote of the functional response of Eurasian oystercatchers eating mussels was actually lowest in winter at the very time when birds' food requirements were highest and the feeding conditions were poorest (Goss-Custard et al., 2001). This led to the untested speculation that there was an unobservable perceptual time cost associated with detecting each consumable prey that, in combination with handling time, limited the rate of feeding, and thus the asymptotic intake rate (Goss-Custard et al., 2001). Alternatively, other activities, such as looking out for more dominant oystercatchers that might attack, could depress the intake rate below the maximum set by handling time (Mitchell \& Brown, 1990).

Such speculations arise because the simple disc equation fails to predict the asymptote from handling time. This is unfortunate because measuring the asymptotic intake rate would be easy if all one had to do was: (i) measure handling time and use its reciprocal to estimate the feeding rate (i.e. number of prey consumed per unit time of active foraging) and then (ii) multiply it by the mean mass of the prey being consumed to determine the intake rate. This paper confirms for a large sample of shorebirds eating macroinvertebrates that this approach is invalid because, at the asymptote, the birds do not spend all their time attacking and handling prey. In the absence of a tested process model upon which to base predictions, this paper instead derives simple empirical equations that allow the asymptotic intake rate to be predicted from a small number of very easily measured variables. It also explores whether the same approach might not also be used to predict the halfasymptote constant of the functional response, i.e. the prey density at which the intake rate rises to half the asymptotic rate.

The paper first describes the functional responses of free-living shorebirds eating macro-invertebrates in which intake rate is expressed as a function of numerical prey density. The second part presents a quite separate data set on 'spot' measurements of intake rate obtained in a particular place at a particular time, usually without prey density being measured. These data were used to derive multiple regression equations with which to predict the asymptotes of the 30 functional responses. This could be done because, 
as the paper shows, the asymptote of the functional response in shorebirds is usually reached at very low numerical prey densities so that most spot estimates of intake rate had probably been obtained when birds were feeding at, or close to, asymptotic rates. We therefore tested whether correlates of the spot measures of intake rates would successfully predict the 30 available estimates of the asymptote.

Many studies of shorebirds require only an estimate of intake rate in a particular bird species eating a particular prey species in a particular time and place and do not require information on the functional response. Since most shorebirds probably mostly fed at the asymptote, the equations developed herein have a second use which is simply to predict the intake rate of shorebirds in a particular place at a particular time far more quickly and easily than is possible with time-consuming conventional field studies. The equations therefore provide a convenient way of estimating intake rate for the many kinds of studies for which the intake rate is a critical piece of information.

\section{METHODS}

This paper draws on two data sets: that for the functional responses and that for the spot estimates of intake rate. It is important to stress that these two data sets are completely separate from each other and often obtained by different research workers. None of the data on 'spot' intake rates were included in any of the studies of the functional responses and vice versa. To have done so, of course, would have introduced a circularity that would have rendered completely invalid the tests we made of the ability of the equations derived from the data set on spot intake rates to predict the observed asymptotes of the functional response.

\section{(1) Functional responses}

The present authors held data sets from which 30 estimates of the asymptote and 23 of the half-asymptote constant of a functional response could be obtained. In all studies, the only activity of the birds during the time over which their intake rate was measured was active foraging; periods when the birds were preening or resting, for example, were excluded. In most cases, the methods used are described in published papers by the authors. The data were taken either from the paper or provided by the author. Some data came from unpublished fieldwork carried out on the Exe estuary over the winters 1998-99 to 2000-01 to increase the number and variety of responses available. Birds were observed throughout the tidal exposure period either from the shore or from a hide in a flat-bottomed boat stranded on the flats as the tide receded. Digital video recorded the feeding activities of individual birds feeding within $100 \mathrm{~m}$; each study plot was therefore approximately 1 ha. Data for one bird species/prey species in one site were obtained over a period of 2-5 tidal cycles. Fifteen sediment samples (surface area $0.00785 \mathrm{~m}^{2}$ ) were taken at random to a depth of $30 \mathrm{~cm}$ and sieved through a $1 \mathrm{~mm}$ mesh to extract the macro-fauna. Individual prey animals were stored in a separate polythene bag and returned to the laboratory and frozen, prior to their length and ash-free dry mass (AFDM) being measured using procedures described in Goss-Custard et al. (2002).

The mean AFDM of the prey consumed by birds was estimated so that the feeding rate could be converted to intake rate; this was done in one of three ways. (1) For oystercatchers opening and leaving emptied clam Scrobicularia plana shells on the mud surface, samples of opened shells were collected. (2) For birds eating the ragworm Hediste diversicolor, samples of droppings were collected to estimate worm length from the length of the mandibles, as described in Durell, Goss-Custard \& Perez-Hurtado (1996). (3) Where neither of these two methods could be used, prey size was estimated as 1.05 times the mean AFDM of the prey in the sediment that were within the birds' size range: see Appendix 1. The mean AFDM of the prey consumed was obtained by converting the lengths of each animal to its AFDM, these being obtained from allometric equations of AFDM against body length. The videos of feeding birds were used to measure the number of prey consumed per minute and, in some cases, the handling time of the prey and the delay imposed on searching by making a failed peck or probe, using the procedure in Goss-Custard \& Rothery (1976). The product of feeding rate (number of prey consumed per second of active foraging) and the mean AFDM of the prey consumed estimated the gross intake rate, defined as milligrams AFDM per second of active foraging.

Interpretation of the functional response is much simplified if the prey items consumed across the full range of numerical prey density are of approximately the same size, measured as AFDM, and prey density is measured as the numerical density of the same size class in the environment. As is explained more fully below, the alternative approach of measuring prey density in terms of the biomass density of the prey causes intake rate to be a function of two factors prey size and prey numerical density - which may not co-vary in simple ways, making interpretation of the response more difficult. So the first step in the analysis was, where it was judged to be necessary, to subdivide the data into sets of approximately uniform prey size. The functional responses presented here relate intake rate on prey of moreor-less constant mass against the numerical density of the same size class of prey in the environment. This is why the number of points in some of the functional responses is sometimes rather low (see below).

The shape of the type II functional response is captured by the asymptotic hyperbolic function:

$$
\text { Intake rate }=a d /(b+d)
$$

where $a=$ asymptote and $d=$ the numerical density of the prey. The coefficient $b$ is the prey density at which intake rate has risen to half its asymptotic level and so is referred to here as the 'half-asymptote constant'. To estimate the two coefficients, $a$ and $b$, equation 1 was applied to the data on intake rate and the numerical density of the prey that lay within the size range normally consumed by the bird (Appendix 1). 


\section{(2) Intake rates}

\section{(a) Sources of the data on intake rates}

Details of location, prey species and methods are given in the source papers. Data were rejected from the analysis if the information given in the source paper was insufficient to establish that the sample size was sufficiently large to provide a reasonable estimate of intake rate and that the data were likely to be reliable: this judgement was based on many years of research in this field by the senior author of this paper. In all studies, the only activity of the birds during the time over which their intake rate was measured was active foraging; periods when the birds were preening or resting, for example, were excluded. Some unpublished and published data were provided as the intake rate of dry mass or of gross or net energy $(\mathrm{kJ})$. These were converted to mgAFDM s ${ }^{-1}$ using the author's own values for assimilation efficiency and energy density of the prey, if stated. In the few cases where these values were unavailable, typical values of assimilation efficiency were taken from the literature: 0.65 for large and heavily-armoured crustaceans (e.g. crabs and large prawns), 0.75 for polychaetes likely to be coated in mud, 0.85 for small crustaceans (e.g. Corophium), 0.75 for molluscs in the shell and 0.85 for bivalve flesh removed from the shell. Energy densities came from Zwarts \& Wanink (1993).

The data sources and the number of estimates of intake rate for each bird species are shown in Table 1. Following Zwarts et al. (1996), the 153 estimates from European oystercatchers eating the heavily armoured prey cockles Cerastoderma edule and mussels were analysed separately. The remaining data, including those from oystercatchers eating prey other than cockles and mussels, are called the 'main data set'.

\section{(b) Correlates of intake rate}

A number of bird and prey variables were used as possible predictor variables of intake rate. Although in many cases only one prey species was consumed, birds sometimes took a mixture of prey. Usually, however, most of the consumption came from a single species: one prey species contributed $>90 \%$ of the consumption in $84 \%$ of the estimates of intake rate. The characteristics of the majority prey species were used as the independent variables in the analysis. The following variables were used:

(i) Prey size. Generally shorebirds attain higher intake rates when eating large prey than when eating small ones (e.g. Ens et al., 1996 c; Zwarts et al., 1996; Goss-Custard et al., 2001). Prey size was measured as the mean AFDM of the consumed prey, including both the majority and minority species, and was either measured directly from the prey size frequency distribution or by dividing intake rate by feeding rate.

(ii) Bird size. Large shorebirds usually have higher intake rates than small ones because their larger gape allows them to swallow larger-sized prey. Additionally, large body size might enable birds to search faster and detect prey over a greater distance, further increasing intake rate. Bird size was measured at their 'basal' body mass in early autumn, after their return from the breeding grounds and before increasing their body reserves. Data were obtained mainly from Cramp \& Simmons (1983) but sometimes from the source papers: the values used are shown in Table 1.

(iii) Prey characteristics. Different prey species have different modes of living, which might affect their vulnerability to shorebirds. For each estimate of intake rate, and using a dummy $0 / 1$ variable, the majority prey species was scored as having (1) or not having (0) the following characteristics: (i) taxon - i.e. polychaete worm or mollusc or crustacean or insect larva (or pupa) or earthworm Lumbricidae or brine shrimp Artemia spp.; (ii) surface-living or burrowing and (ii) whether it is an active prey able to retreat into a burrow to avoid bird predators (e.g. Hediste diversicolor). Thus, if the majority prey species was $\mathcal{N}$. diversicolor, the scores would be: polychaete (1), mollusc (0), crustacean (0), insect (0), earthworm (0), Artemia (0), surface-living (0), active (1).

(iv) Bird characteristics. Oystercatchers were disproportionately represented so a dummy $0 / 1$ variable was used to identify this species in case it had a singular and overinfluential effect on the results.

Dummy 0/1 variables distinguished (i) visual (1) from tactile $(0)$ foragers, (ii) the 'stand-and-wait' plover search strategy (1) from the more continuously searching 'sandpiper' (0) strategy, (iii) breeding birds (1), with eggs or young, from non-breeders (0), and (iv) adults (1) from subadults $(0)$ : as there were many missing values for bird age, its effect was only explored after the various models had already been selected.

Interference competition is widespread in shorebirds (Stillman et al., 2002) but its possible influence on intake rate could not be considered as bird density and/or the occurrence of aggressive interactions was usually unreported. However, most of the data were collected over low tide when birds would have been able to spread out, keeping interference to a minimum.

Latitude might have an effect because of a global trend for prey diversity to be higher near the equator (Piersma et al., 1993), or because temperature influences prey activity. It was represented as minutes north or south of the equator.

\section{(3) Statistical Analyses}

Strictly, our observations of intake rate are not independent of one another. Our data were structured such that we had 468 separate estimates of intake rate collected over 26 species from 11 genera within the Charadriiformes. We therefore first explored our data using Generalised Linear Mixed Models (GLMMs) with the random effects structured in a hierarchical manner (Goldstein, 2003). In other words, we specified that the three random effects, namely observation, species and genus, were structurally nested. We then entered the fixed effects discussed above as independent explanatory variables. We found that the same set of independent variables was retained in the final model irrespective of whether we used GLMMs or the more simple Generalised Linear Models (GLMs). The 
Table 1. The species and sample sizes available for the analysis of variation in intake rates. Basal body mass is the mass of the species in early autumn, as obtained from Cramp \& Simmons (1983). Species are listed in ascending order of body mass.

\begin{tabular}{|c|c|c|c|c|c|}
\hline Species & & $\mathcal{N}$ & $\begin{array}{l}\text { Basal } \\
\text { body } \\
\text { mass (g) }\end{array}$ & Sources of unpublished data & Sources of published data \\
\hline Little stint & Calidris minuta & 6 & 23.1 & G. Eichhorn; J. A. Masero & Eichhorn (2001), Masero (2003) \\
\hline Kittlitz's plover & Charadrius pecuarius & 23 & 41.8 & B. Kalejta-Summers & \\
\hline Kentish plover & Charadrius alexandrinus & 6 & 42.7 & M. Castro & Castro (2001) \\
\hline Sanderling & Calidris alba & 4 & 48.5 & V. Dierschke; J. A. Masero & Masero (2003) \\
\hline Dunlin & Calidris alpina & 14 & 48.8 & V. Dierschke; K.-M. Exo; J. A. Masero & $\begin{array}{l}\text { Dierschke (1998), Dierschke et al. (1999), Düsing (1995), Masero (2003), Müller (1999), } \\
\text { Petersen (1995) }\end{array}$ \\
\hline Curlew sandpiper & Calidris ferruginea & 18 & 51.0 & J. A. Masero \& A. Perez-Hurtado & Kalejita (1992), Kalejta \& Hockey (1994), Martin (1991), Velasquez (1993) \\
\hline Ringed plover & Charadrius hiaticula & 4 & 55.0 & B. Kalejta-Summers; J. A. Masero & Hockey et al. (1999), Masero (1998), Pienkowski (1982) \\
\hline Mongolian plover & Charadrius mongolus & 1 & 58.0 & & Hockey et al. (1999) \\
\hline Purple sandpiper & Calidris maritima & 6 & 68.4 & & Dierschke (1993) \\
\hline Terek sandpiper & Xenus cinereus & 2 & 74.0 & & Piersma $(1986 b)$ \\
\hline Greater sand plover & Charadrius leschenaultii & 1 & 106.0 & & Hockey et al. (1999) \\
\hline Turnstone & Arenaria interpres & 1 & 110.0 & & Martin (1991) \\
\hline Knot & Calidris canutus & 8 & 120.0 & $\begin{array}{l}\text { J. D. Goss-Custard \& A. D. West; } \\
\text { J. A. Masero; D. Rogers }\end{array}$ & Alerstam et al. (1992), Moreira (1994a), Piersma et al. (1993) \\
\hline Redshank & Tringa totanus & 7 & 126.0 & $\begin{array}{l}\text { K.-M. Exo; J. A. Masero \& } \\
\text { A. Perez-Hurtado }\end{array}$ & $\begin{array}{l}\text { Cresswell (1994), Goss-Custard (1977 a, b, d), Moreira (1996), } \\
\text { Masero \& Perez- Hurtado (2001), Müller (1999), Petersen (1995) }\end{array}$ \\
\hline Great knot & Calidris tenuirostris & 4 & 155.0 & D. Rogers & Tulp \& de Goeij (1994) \\
\hline Blacksmith's plover & Vanellus armatus & 3 & 165.0 & B. Kalejta-Summers & \\
\hline Greenshank & Tringa nebularia & 1 & 174.0 & & Martin (1991) \\
\hline Grey plover & Pluvialis squatarola & 19 & 219.0 & K.-M. Exo; J. A. Masero & $\begin{array}{l}\text { Hockey et al. (1999), Kalejta (1992), Kalejta \& Hockey (1994), Kersten \& Piersma (1984), } \\
\text { Krüger (1997), Martin (1991), Masero (1998), Moreira (1996), Müller (1999), } \\
\text { Pienkowski (1982), Turpie \& Hockey (1993, 1996, 1997), Wahls \& Exo (1996), } \\
\text { Wolff (2000) }\end{array}$ \\
\hline Black-tailed godwit & Limosa limosa & 13 & 228.0 & $\begin{array}{l}\text { J. D. Goss-Custard \& A. D.West; } \\
\text { J. A. Masero \& A. Perez-Hurtado }\end{array}$ & Moreira $(1994 b)$ \\
\hline Bar-tailed godwit & Limosa lapponica & 33 & 321.0 & $\begin{array}{l}\text { K.-M. Exo; J. D. Goss-Custard \& } \\
\text { A. D. West; G. Scheiffarth }\end{array}$ & Scheiffarth (2003), Smith (1975), Wolff (2000) \\
\hline Crab plover & Dromas aedeola & 6 & 325.0 & & Hockey et al. $(1996,1999)$ \\
\hline Whimbrel & Numenius phaeopus & 5 & 385.0 & & Martin (1991), Turpie \& Hockey (1996; 1997), Zwarts (1985) \\
\hline $\begin{array}{l}\text { European } \\
\text { oystercatcher }\end{array}$ & Haematopus ostralegus & 257 & 500.0 & $\begin{array}{l}\text { R. W. G. Caldow; S. Durell; B. J. Ens; } \\
\text { K.-M. Exo; J. D. Goss-Custard; } \\
\text { J. D. Goss-Custard \& A. D. West; } \\
\text { M. G. Yates; L. Zwarts; } \\
\text { A. Perez-Hurtado }\end{array}$ & $\begin{array}{l}\text { Blomert et al. (1983), Boates \& Goss-Custard (1989, 1992), Brown \& O’Connor (1976), } \\
\text { Bunskoeke (1988), Bunskoeke et al. (1996), Cayford \& Goss-Custard (1990), } \\
\text { Davidson (1967), Drinnan (1957, 1958), Durell et al. (1996), Ens \& Goss-Custard (1984), } \\
\text { Ens et al. (1993, 1996 a, b, c), Goss-Custard (1977 c), Habekotté (1987), Heppleston (1971), } \\
\text { Hosper (1978), Hulscher (1976, 1982), Hulscher et al. (1996), Koene (1978), } \\
\text { Leopold et al. (1989), Maagaard \& Jensen (1994), Meire (1996a, b), Meire \& Eryvynck (1986), } \\
\text { Müller (1999), Nagarajan (2000), Petersen (1995), Sitters (200), Speakman (1987), } \\
\text { Swennen (1990), Triplet (1989), Umland (2000), Veenstra (1977), Wanink \& Zwarts (1985), } \\
\text { Wolff (2000), Zwarts \& Blomert (1996), Zwarts \& Drent (1981), Zwarts \& Wanink (1984), } \\
\text { Zwarts et al. (1996) }\end{array}$ \\
\hline $\begin{array}{l}\text { American } \\
\text { oystercatcher }\end{array}$ & Haematopus palliatus & 3 & 603.0 & C. Pacheco & Cadman (1980), Pacheco \& Castilla (2000) \\
\hline Curlew & Numenius arquata & 21 & 757.0 & $\begin{array}{l}\text { K.-M. Exo; J. D. Goss-Custard } \\
\text { \& A. D. West }\end{array}$ & $\begin{array}{l}\text { Ens et al. (1990), Martin (1991), Petersen (1995), Rippe \& Dierschke (1997), } \\
\text { Siman (1989), Wolff (2000), Umland (2000), Zwarts (1985) }\end{array}$ \\
\hline Eastern curlew & $\begin{array}{l}\text { Numenius } \\
\text { madagascariensis }\end{array}$ & 2 & 764.0 & & Piersma (1986a), Yi et al. (1994) \\
\hline
\end{tabular}

Hockey et al. $(1996,1999)$

Martin (1991), Turpie \& Hockey (1996; 1997), Zwarts (1985)

Bers Davidson (1967), Drinnan (1957, 1958), Durell et al. (1996), Ens \& Goss-Custard (1984), Ens et al. (1993, $1996 a, b, c)$, Goss-Custard (1977c), Habekotté (1987), Heppleston (1971), (a)

, et al. (1989), Maagaard \& Jensen (1994), Meire (1996 a, b), Meire \& Eryyynck (1986),

(1991), Petersen (1995), Rippe \& Dierschke (1997), Siman (1989), Wolff (2000), Umland (2000), Zwarts (1985) 
main difference between the results of our two modelling approaches was in the standard errors estimated for each parameter estimate - this is to be expected since GLMMs are explicitly structured to provide more accurate estimates of the error around each parameter where the data are not independent of one another (Goldstein, 2003). For example, our two-variable GLM model that we discuss in the Results gave parameter estimates of intake rate (with the S. E. M. shown in parentheses) according to the equation:

$\log _{\mathrm{e}}$ intake rate $\sim 2 \cdot 977(0 \cdot 196)+0 \cdot 303(0 \cdot 043)$

$\times \log _{\mathrm{e}}$ body mass $+0 \cdot 323(0 \cdot 018) \log _{\mathrm{e}}$ prey mass

These parameter estimates are not dissimilar to the estimated fixed effects of $2.867(0.405)$ for the intercept and $0.273(0.085)$ and $0.337(0.019)$ for $\log _{e}$ of body mass and prey mass, respectively, obtained from the GLMM run on the same data.

We therefore present our results using GLMs in the main text of this paper, but provide the results from the GLMMs in Appendix 2. The main reason for adopting this approach is that our motivation in this paper is easily to predict coefficients of the functional response in freeliving animals: GLMs allow simple back-transformation of $\log _{\mathrm{e}}$ predicted values, and also provide estimates of coefficients of determination $\left(r^{2}\right.$ values $)$. These latter are not readily available from GLMMS - indeed, there is considerable debate as to the meaning of such coefficients in a mixed modelling framework (cf. Snijders \& Bosker, 1999, Goldstein, 2003).

We therefore present in full only the results from GLMs in order to identify the correlates of intake rate. Transforming intake rates, prey mass and bird body mass to logarithms satisfactorily stabilised the variance. The interaction term between the $\log _{\mathrm{e}}$ bird mass and $\log _{\mathrm{e}}$ prey mass was also included. All the other predictor variables were dummy 0/1 variables except for latitude, which was untransformed. MINITAB 13 was used to identify first the best-fitting model in which all the included variables had significance level of $<5 \%$.

In the case of the European oystercatchers eating mussels and cockles, the multiple regression analysis included the mean AFDM of the consumed prey $\left(\log _{\mathrm{e}}\right)$ along with $0 / 1$ dummy variables representing whether birds (a) fed by sight (1) or by touch (0); (b) opened shells by hammering (1) or stabbing $(0)$; (c) were breeding or not (1) or not $(0)$, and $(\mathrm{d})$ were in captivity $(1)$ or free-living $(0)$ and whether the prey was a cockle (1) or mussel (0). In addition, the time taken by the birds to handle a typical-sized cockle $(25 \mathrm{~mm})$ and mussel $(45 \mathrm{~mm})$ was included because thick shells, and the associated long handling times, could reduce intake rate. This was done by expressing the observed handling time as a ratio against the typical value for a cockle or mussel of these lengths, obtained from the equations given in Zwarts et al. (1996). The typical values were: (a) $20.2 \mathrm{~s}$ and $28.3 \mathrm{~s}$ for $25 \mathrm{~mm}$ cockles opened by stabbing and hammering, respectively, and (b) $59.7 \mathrm{~s}$, $103.2 \mathrm{~s}$ and $105.5 \mathrm{~s}$ for $45 \mathrm{~mm}$ mussels opened by stabbing, dorsal hammering and ventral hammering, respectively.
Where no data on handling times were available, the ratio was assumed to be 1 .

\section{RESULTS}

\section{(1) Functional response}

\section{(a) Asymptote and half-asymptote constant}

In most functional responses, intake rates varied independently of numerical prey density over a wide range but were often highly variable at a particular density (Fig. 1). A multiple regression analysis of intake rate against mean prey mass and numerical prey density showed that much of this variation reflected differences between sites in the mean AFDM of the prey (Table 2). Prey density was either untransformed or the square root or cube root taken to capture its possible non-linear effect on intake rate. In 16 of the 23 cases with sufficient data for analysis, prey mass had a highly significant positive effect on intake rate, much more often than did prey density (6).

In estimating the coefficients of the functional response, the data were therefore divided into subsets according to prey size because, where prey size varies greatly between sites, biased estimates of the asymptote can arise. For example, if some sites have low densities of small prey (and thus low intake rates) while others have high densities of large prey (and thus high intake rates), the fitted functional response gives a very high estimate of the asymptote; this may explain why, compared with other studies, the asymptote was so high in the functional response of intake rate against prey biomass density produced for touchfeeding oystercatchers eating cockles by Norris \& Johnstone $(1998 b)$. Subsetting the data by prey size enabled both coefficients of the asymptotic hyperbolic functions to be estimated in 23 cases. In the remaining seven, there were no data at low prey densities so the half-asymptote constant could not be estimated. However, prey densities were generally so high in these cases that it can be safely assumed that intake rates had reached the asymptote (Fig. 1), so the mean intake rate was used as the estimate of the asymptote.

The asymptote, $a$, varied between 0.183 and $3.117 \mathrm{mgAFDM} / \mathrm{s}$ (Table 3 ). The prey density at which intake rate reached $50 \%$ of its asymptotic value, $b$, also varied, but in most cases had very low values, i.e. the gradients were generally steep relative to the range in prey density observed. In 21 of 23 estimates, intake rate reached half its asymptotic value before prey density had reached only 65/ $\mathrm{m}^{2}$, which is very low compared with the high prey densities recorded in most studies (Fig. 1). The two exceptions were for black-tailed godwit Limosa lapponica eating small bivalve molluscs in SE England.

\section{(b) Proportion of foraging time spent attacking and handling prey}

Across 11 studies on four species, birds spent on average only $51.4 \%$ (S.E.M. $=4.7$; range $28.0 \pm 2.1-78.4 \pm 3.2 \%$ ) of their foraging time pecking at and attacking prey, either 
successfully or unsuccessfully (Table 4). The remaining time was spent searching; in all but the continuously probing godwit, the birds walked with head aloft, apparently searching visually for prey.

\section{(2) Intake rates}

\section{(a) European oystercatchers eating cockles and mussels}

Of the 152 spot estimates of intake rate available for European oystercatchers eating heavily-armoured prey, 46 were of birds eating cockles and 106 eating mussels. Feeding method, sensory modality and handling time did not have a significant effect on $\log _{e}$ intake rate and were rejected in that order in a step-down regression analysis with $P$ values of $0.43,0.19$ and 0.11 , respectively. The following had highly significant effects (adj. $R^{2}=61.8 \%$, $P<0.001$ ), the values in parentheses showing the coefficient, its S.E.M. and $P$-value respectively: $\log _{\mathrm{e}}$ prey mass $(+0.474,0.032,<0.001)$, whether the prey was a mussel $(-0.346,0.085,<0.001)$, whether the bird was breeding $(+0.525,0.146,<0.001)$ and being held in captivity $(-0.366,0.153,0.018)$ : the constant was -1.801 (S.E.M. =0.157, <0.001). Intake rate increased with prey mass and was higher in breeding birds but lower in musseleaters and in captive oystercatchers.

\section{(b) Other bird and prey species}

Although the sample included 26 species of 11 genera (Table 1), oystercatchers eating non-armoured prey (i.e. not cockles or mussels) dominated so the analysis was first conducted with oystercatchers excluded. Ten variables had a significant effect on intake rate (Table 5, column 2). In addition to bird mass and prey mass (but not their interaction), variables representing prey taxon and other prey characteristics were selected: intake rates were lower when the prey could retreat down burrows, were molluscs or were crustaceans. Taking all other significant variables into account, breeding birds had higher intake rates whereas birds using the plover foraging strategy had lower intake rates and birds fed more slowly as their distance from the equator increased.

The analysis on just oystercatchers eating non-armoured prey selected five variables of which two were again prey mass and whether the birds were breeding (Table 5, column 3). With the data for oystercatchers combined with those from all the other species, nine variables were selected (Table 5, column 4). Apart from bird mass and prey mass, and their interaction, a number of prey and bird characteristics were again selected, including whether the birds were breeding and were oystercatchers. Essentially the same variables were selected when oystercatchers eating cockles and mussels were also included in the analysis (Table 5, column 5). Breeding birds again fed faster than nonbreeders while oystercatchers eating mussels had a lower intake rate.

In all analyses, $R^{2}$ values (adjusted) were surprisingly high, varying between 68.0 and $81 \%$ (Table 5). But despite their high levels of statistical significance, many variables had only a small absolute effect on intake rate and made little contribution to the amount of variance explained. Accordingly, $R^{2}$ was still $77.3 \%$ with only four of the most consistently selected variables included: bird mass, prey mass (but not their interaction) and whether the bird was an oystercatcher eating mussels or breeding (Table 5, column 6). (With no data transformed to logarithms, $R^{2}$ was only reduced to $61 \%$.). Indeed, $\log _{\mathrm{e}}$ bird and prey masses alone accounted for only $2 \%$ less of the variation in $\log _{\mathrm{e}}$ intake rate (Table 5 , column 7 ). Despite the very wide variety of prey species, habitats, study methods and research workers involved, a surprisingly high proportion of the variance in shorebird intake rate could be accounted for by very few variables.

Adding the dummy variable expressing the bird's age in the much smaller data sets where bird age was known did not add significantly to any of the equations in Table 5, although in all cases, the sign of the coefficient implied that any effect would have been for adults to feed faster than young, as previously shown by Hockey, Turpie \& Velasquez (1998).

\section{(3) Predicting the coefficients of the functional response}

\section{(a) Asymptote}

The equations in columns 6 and 7 of Table 5 were used to predict the asymptotes of the functional responses shown in Table 2. Because of the effect that taking logarithms can have on sample variance, the following Error Mean Square back-transformation correction was applied to the predictions (Newman, 1993). The uncorrected predicted $\log _{\mathrm{e}}$ intake rate, $Z$, was calculated from the Table 5 equations and corrected as follows:

$$
\text { Intake rate }=\exp \left(Z+S^{2} / 2\right)
$$

where $S^{2}=$ Error Mean Square (or Residual Mean Square) of the regression (bottom row of Table 5).

The correlation between observed and predicted asymptotes from the four-variable model (Table 5, column 6) was quite close (Fig. 2, filled circles). The intercept, $i$, of the observed:predicted regression (not shown in Fig. 2) was not significantly different from $0(i=0.083$, S.E.M. $=0.116$; $P=0.474)$ and the slope, $s$, was not significantly different from $1 \quad(s=0.985$, S.E.M. $=0.075 ; P=0.735)$. On average, the four-variable equation under-predicted observed asymptotes by $11.6 \%$ (range $-204.0 \%$ to $+53.1 \%$, $\mathcal{N}=30$ ) but, as its S.E.M. was $9.5 \%$, the mean discrepancy was not significantly different from zero. Much of this discrepancy arose from two very high values obtained in an early study of redshank Tringa totanus eating Corophium volutator on the Ythan estuary by J. D.Goss-Custard when the methodology for measuring intake rates in shorebirds was poorly developed; for instance, feeding rate was overestimated because it was measured from inter-catch intervals (Goss-Custard et al., 2002). With these two points excluded, the observed asymptotes were on average only $0.2 \%$ (S.E.M. $=5.05$; range $-59.0 \%$ to $+53.1 \%, \mathcal{N}=28$ ) higher than the predicted values. 

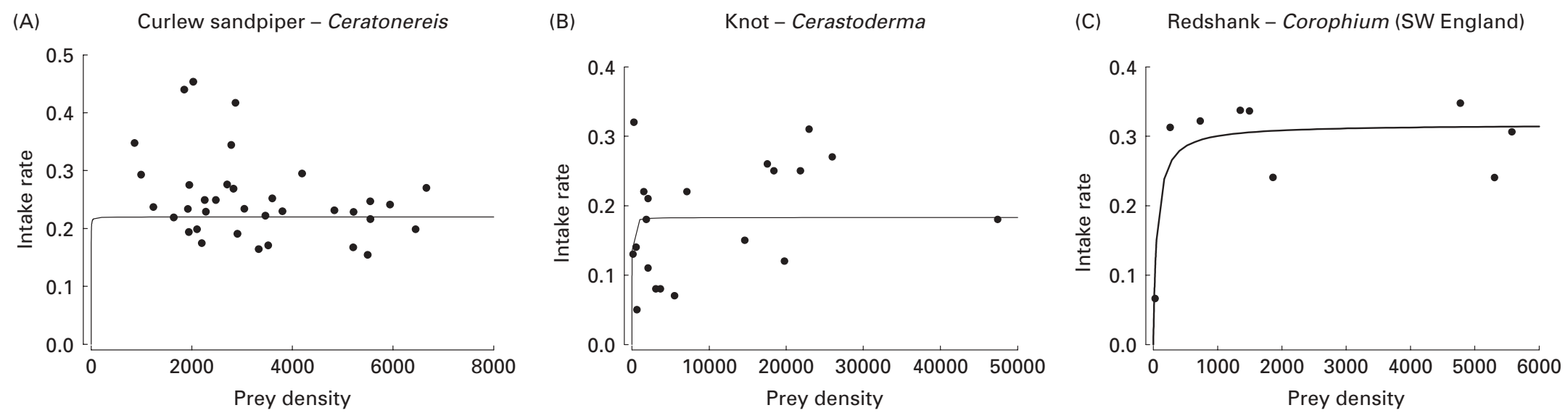

(D) Redshank - Corophium (Ythan estuary)

(E)

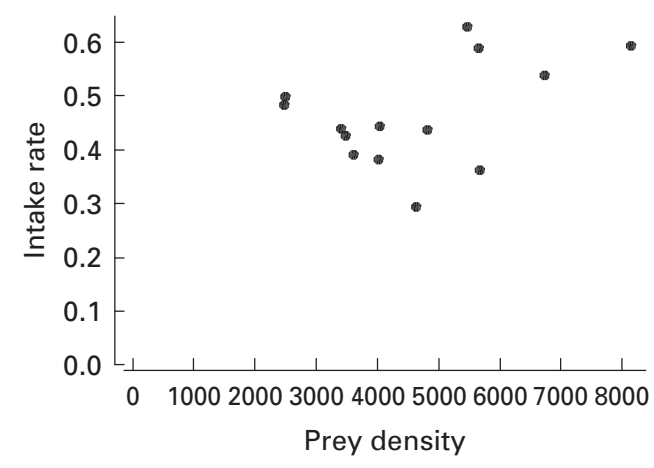

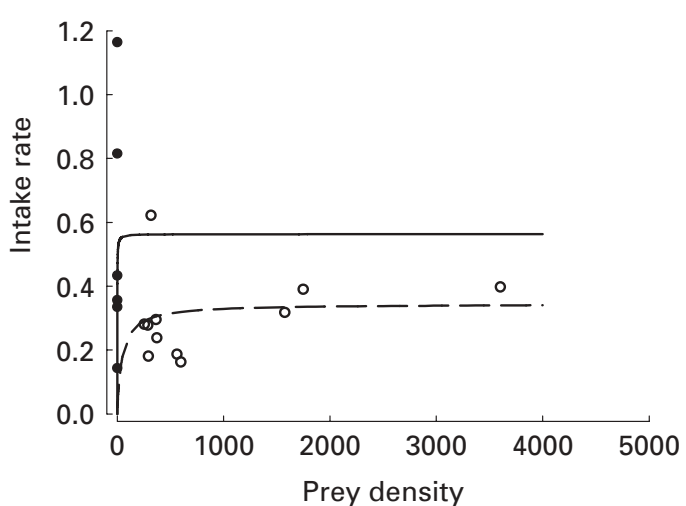

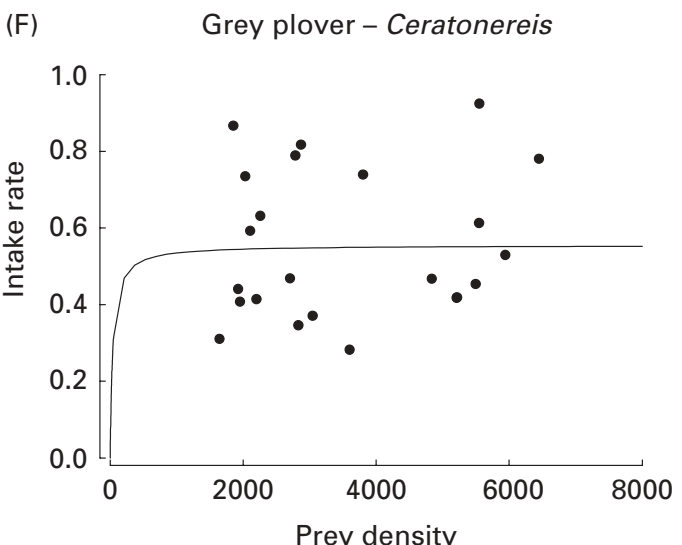


(G) Black-tailed godwit - bivalves (SE England)
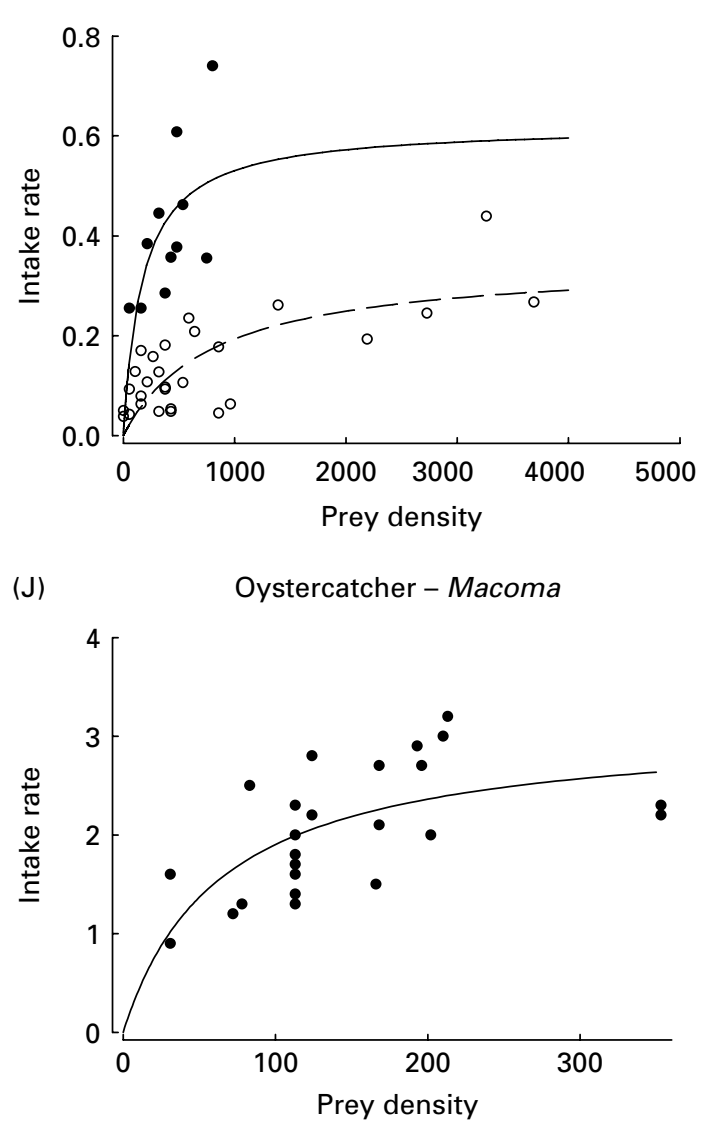

Black-tailed godwit - Scrobicularia (Exe estuary)

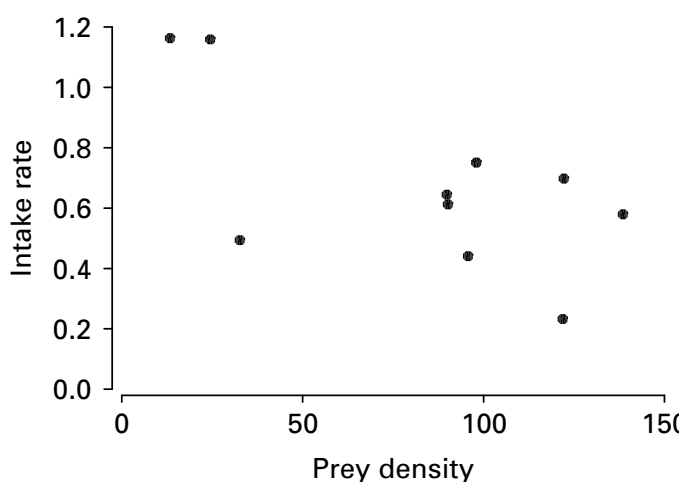

(K)

Oystercatcher - Scrobicularia

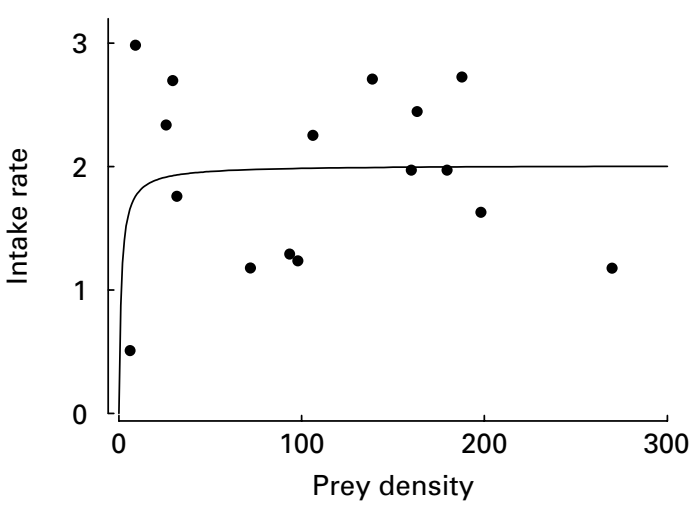

Black-tailed godwit - Lumbricidae

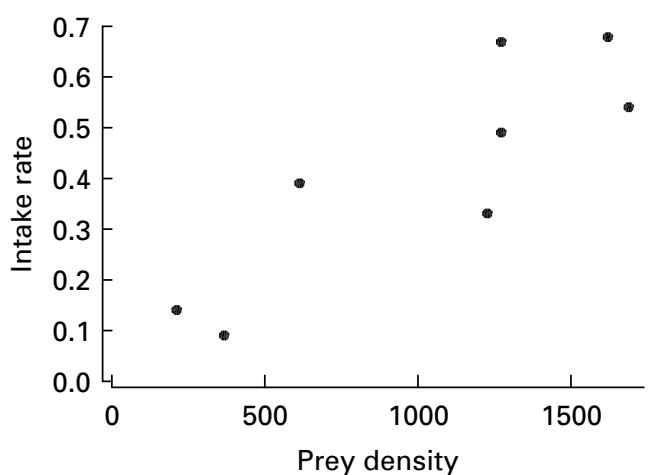

(L)

Oystercatcher - Hediste

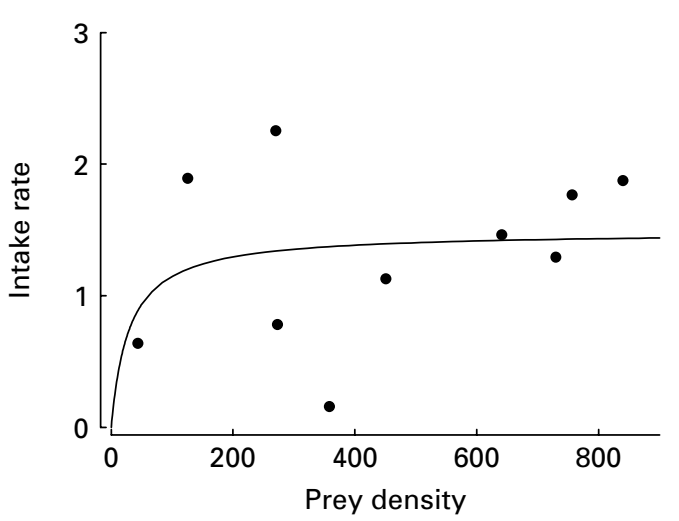

Fig. 1. (cont.) 
(M) Oystercatcher (S) - Cerastoderma (Wadden Sea)

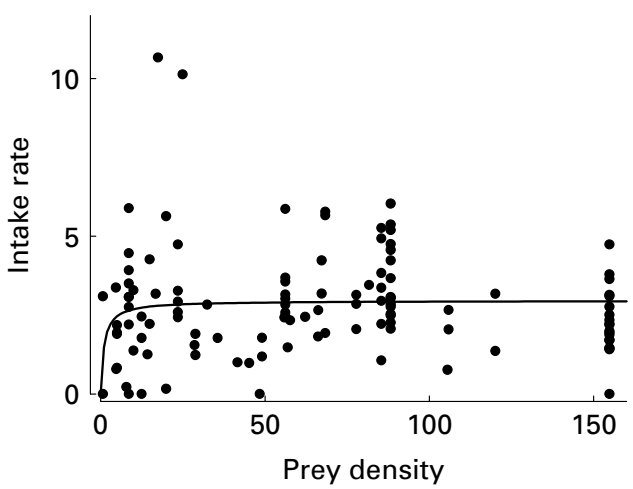

(P) Oystercatcher (S) - Cerastoderma (Traeth Melynogg)

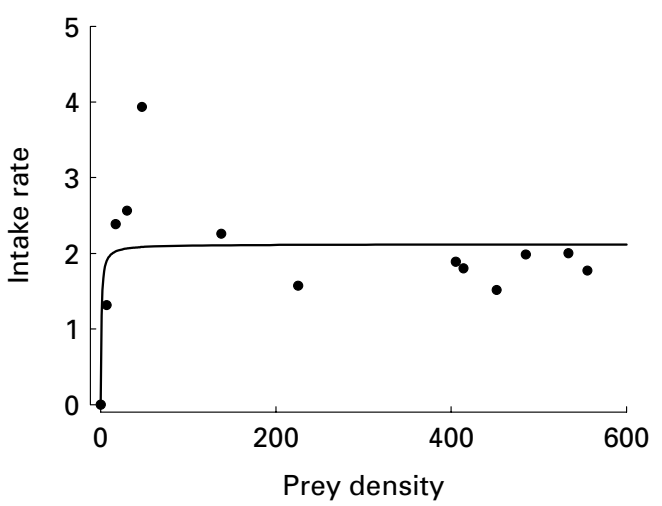

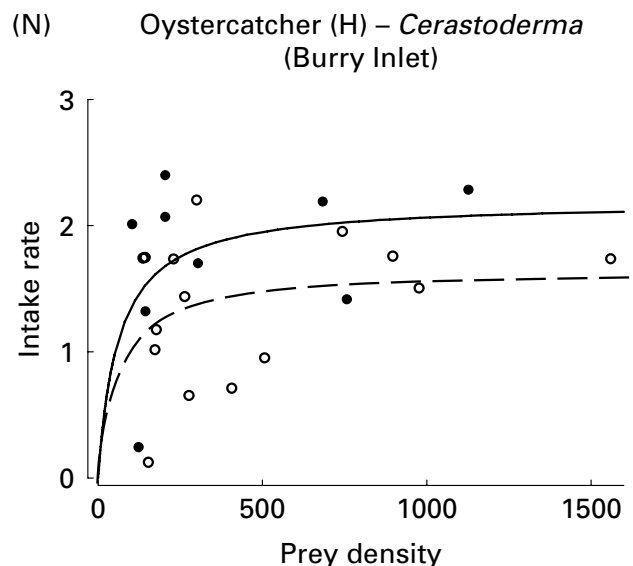

(Q) Oystercatcher (S) - Mytilus (Exe estuary)

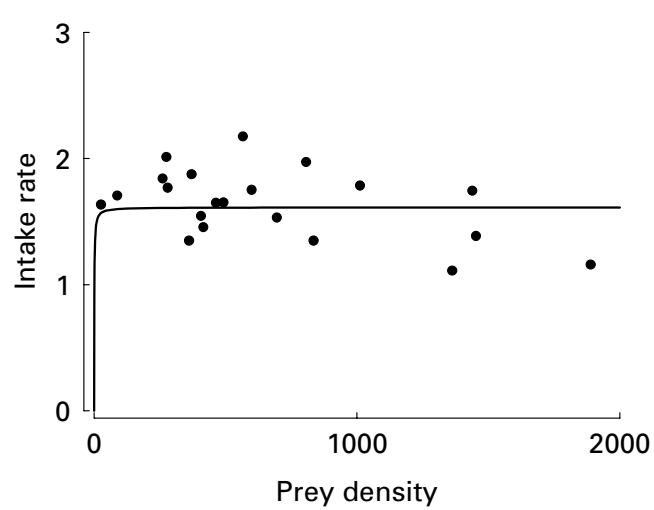

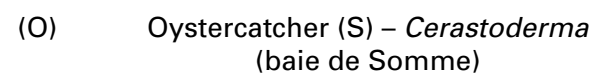

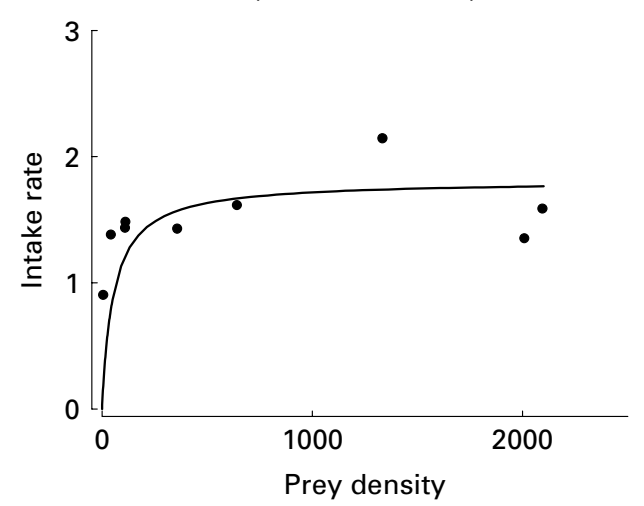

(R) Oystercatcher (D) - Mytilus (Exe estuary)

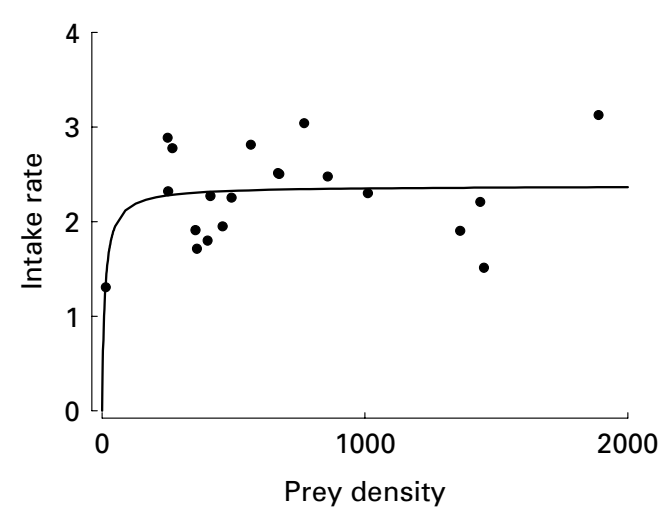


(S)

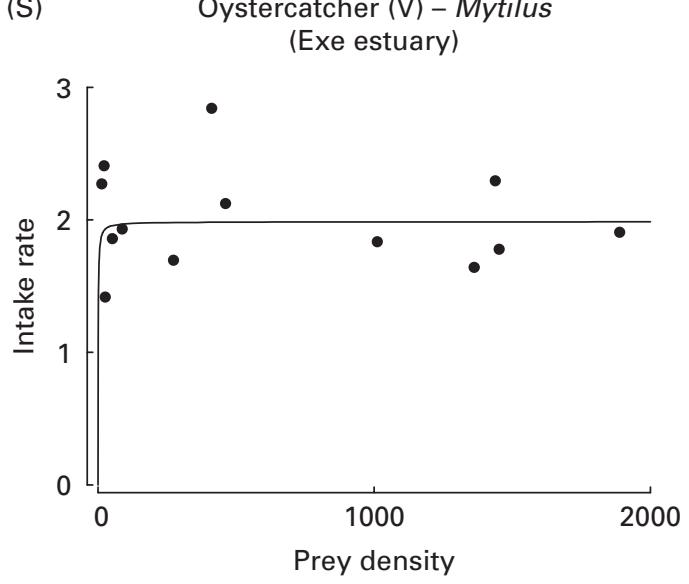

(V) Curlew - Hediste (Wadden Sea)

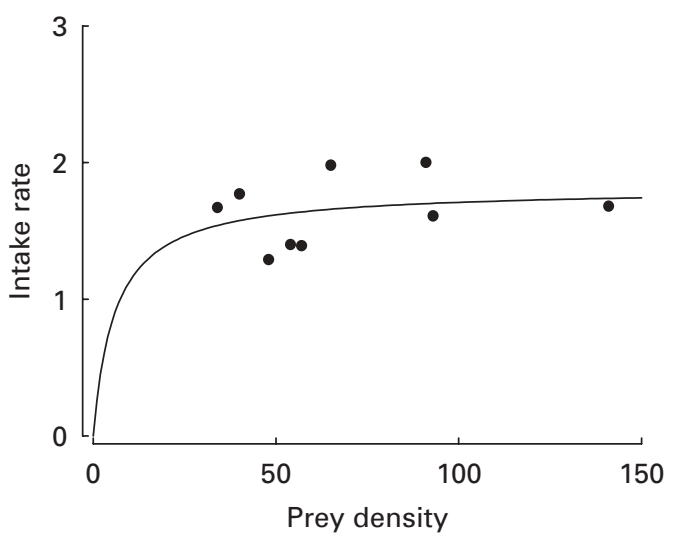

(T)

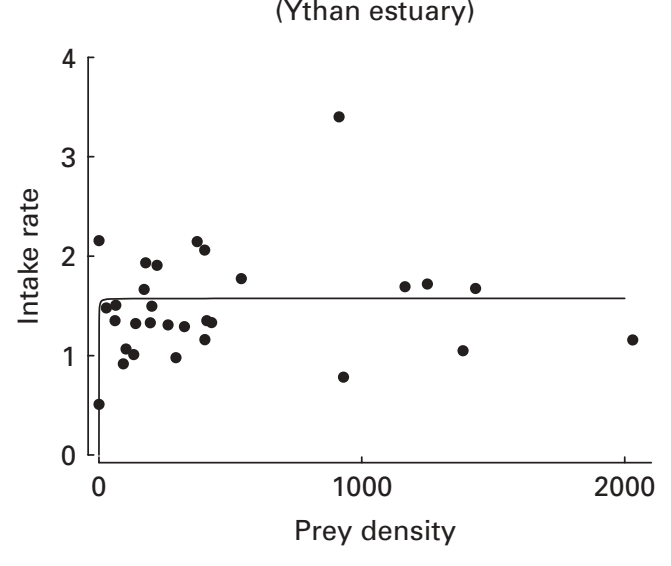

(W)

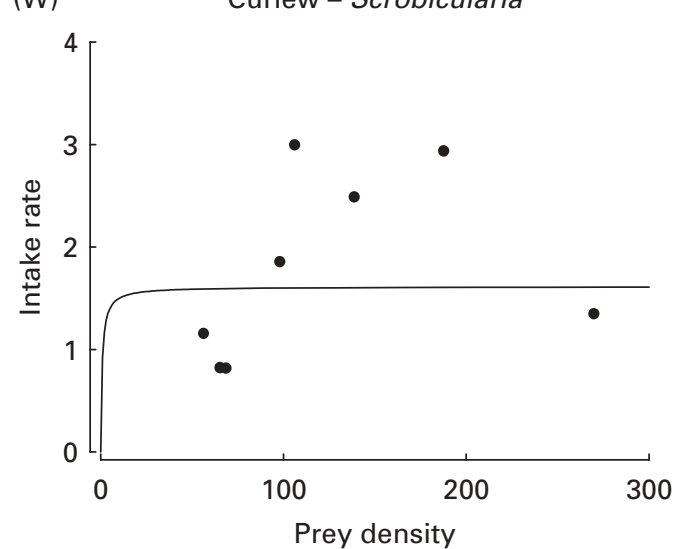

(U)

Curlew - Hediste (Exe estuary)

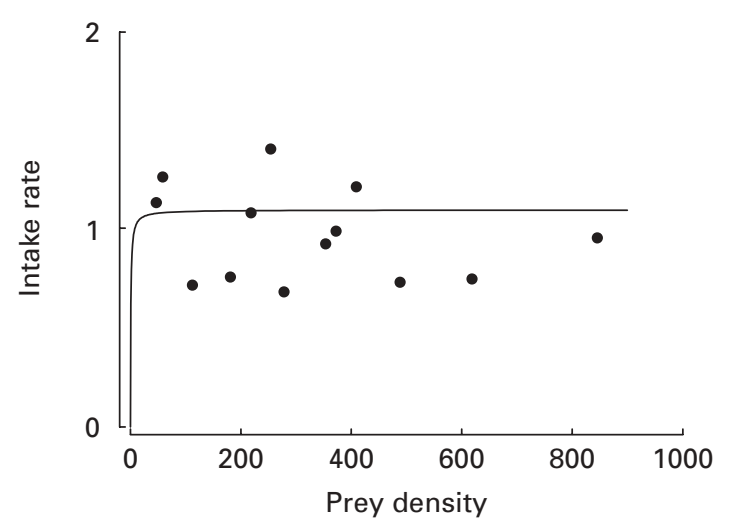

$(\mathrm{X})$

Eastern curlew - Trypaea

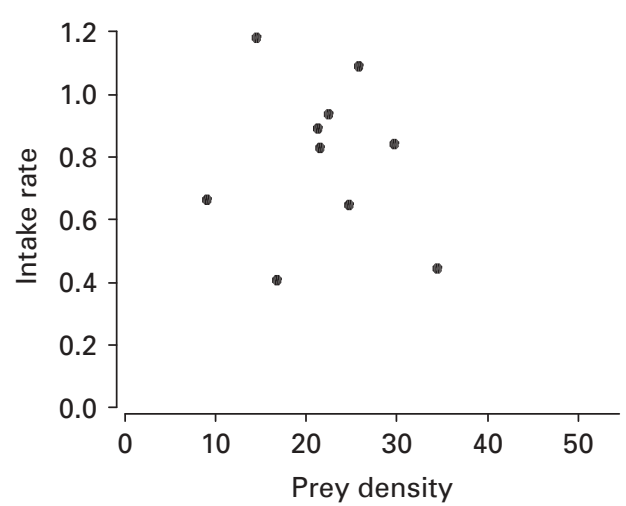

Fig. 1. Functional responses of shorebirds eating macro-invertebrates whose generic name is shown after the English name for the bird: intake rate (mg ash-free dry mass $\mathrm{s}^{-1}$ ) against numerical density of the prey (number $\mathrm{m}^{-2}$ ). Except for $\mathrm{M}$ where each point is a 10 min feeding observation, each point represents the mean intake rate and prey density in a single site over a single study period that varied in length from days to weeks in cases where prey density changed very slowly. In oystercatchers eating cockles and mussels (M-T), S means they fed by stabbing, D and V mean that the birds hammered into mussel shells on the dorsal and ventral sides, respectively, and $\mathrm{H}$ means they hammered into cockles. Species are shown in ascending order of body size. All studies were conducted during the non-breeding season except for studies (J) and (M). The solid lines show the fitted asymptotic hyperbolic functions (equation 1) either for prey of all sizes or just for large prey, the data points for which are filled circles. Dashed lines show the fitted asymptotic hyperbolic functions for the small prey alone, the data points for which are open circles. No curves are fitted where the data range and/or sample size were insufficient to calculate the parameters of the asymptotic hyperbolic function. 
Table 2. Correlates of intake rates $\left(\mathrm{mgAFDMs}^{-1}\right)$ of the functional responses shown in Fig. $1 . \mathcal{N}$ is the number of sites for which a mean intake rate value was obtained from a sample of birds [except for one study of oystercatchers (Fig. 1M) where $\mathcal{N}$ refers to the number of 10 -min feeding observations]. The values in columns 'Prey mass' and 'Prey density' show the sign (positive or negative) immediately adjacent to the $P$-value (positive values at $5 \%$ significance level or less shown in bold) for the individual effect of each of these two variables (in the presence of the other) in a multiple regression analysis. The adjusted $R^{2}$ value and the $P$-value for the multiple regression equation as a whole are shown in the next two columns. The final column shows whether numerical prey density was transformed by square root (S) or cube root (C) transformation, or was expressed in the linear $(\mathrm{L})$. Species are listed in ascending order of body mass, as given in Table 1. Curlew eating Neries diversicolor in the Wadden Sea are not included here as prey size was the same in all sites. S, D, V in parentheses for four of the oystercatcher studies indicates oystercatchers feeding on mussels by stabbing $(\mathrm{S})$, or hammering on the dorsal $(\mathrm{D})$ or ventral $(\mathrm{V})$ sides.

\begin{tabular}{|c|c|c|c|c|c|c|c|c|c|}
\hline Bird species & Prey & Study area & Source of data & $\mathcal{N}$ & Prey mass & $\begin{array}{l}\text { Prey } \\
\text { density }\end{array}$ & $r^{2}$ & $P$ & $\begin{array}{l}\text { Trans- } \\
\text { formation }\end{array}$ \\
\hline Curlew sandpiper & Ceratonereis spp. & Berg estuary, South Africa & B. Kalejta-Summers & 37 & $<0.001$ & -0.796 & 0.587 & $<0.001$ & $\mathrm{C}$ \\
\hline Knot & Cerastoderma edule & Wash, England & M. G. Yates \& J. D. Goss-Custard & 21 & 0.008 & 0.009 & 0.364 & 0.008 & $\mathrm{~L}$ \\
\hline Redshank & Corophium volutator & Estuaries in SW, England & J. D. Goss-Custard & 9 & 0.075 & 0.231 & 0.426 & 0.080 & $\mathrm{G}$ \\
\hline Redshank & Corophium volutator & Ythan estuary, Scotland & J. D. Goss-Custard & 14 & 0.002 & -0.281 & 0.603 & 0.002 & C \\
\hline Redshank & Hediste diversicolor & Estuaries in SW, England & J. D. Goss-Custard & 17 & $<0.001$ & 0.003 & 0.952 & $<0.001$ & $\mathrm{~L}$ \\
\hline Grey plover & Ceratonereis spp. & Berg estuary, South Africa & B. Kalejta-Summers & 25 & 0.914 & 0.989 & $<0.001$ & 0.994 & $\mathrm{~S}$ \\
\hline Black-tailed godwit & Bivalva & Estuaries in SE England & J. A.Gill & 39 & $<0.001$ & $<0.001$ & 0.730 & $<0.001$ & $\mathrm{C}$ \\
\hline Black-tailed godwit & Scrobicularia plana & Exe estuary, England & J. D. Goss-Custard \& A. D. West & 10 & 0.002 & -0.015 & 0.855 & $<0.001$ & G \\
\hline Black-tailed godwit & Lumbricidae & Southern England & J. A. Gill & 8 & 0.741 & 0.011 & 0.657 & 0.030 & C \\
\hline Oystercatcher & Macoma balthica & Wadden Sea, The Netherlands & B. J. Ens & 24 & -0.388 & 0.055 & 0.317 & 0.007 & C \\
\hline Oystercatcher & Scrobicularia plana & Exe estuary, England & J. D. Goss-Custard \& A. D. West & 17 & 0.007 & 0.180 & 0.338 & 0.022 & $\mathrm{~L}$ \\
\hline Oystercatcher & Hediste diversicolor & Exe estuary, England & J. D. Goss-Custard \& A. D. West & 10 & 0.388 & 0.256 & $<0.001$ & 0.501 & G \\
\hline Oystercatcher & Cerastoderma edule & Wadden Sea, The Netherlands & B. J. Ens & 115 & 0.002 & 0.133 & 0.068 & 0.007 & G \\
\hline Oystercatcher & Cerastoderma edule & Burry Inlet, Wales & I. Johnstone & 24 & 0.007 & 0.078 & 0.368 & 0.007 & $\mathrm{~S}$ \\
\hline Oystercatcher & Cerastoderma edule & Baie de Somme, France & P. Triplet & 9 & -0.782 & 0.387 & 0.152 & 0.258 & C \\
\hline Oystercatcher & Cerastoderma edule & Traeth Melynogg, Wales & W.J. Sutherland & 12 & 0.007 & 0.045 & 0.543 & 0.012 & C \\
\hline Oystercatcher (S) & Mytilus edulis & Exe estuary, England & J. D. Goss-Custard, S. Durell \& A. D. West & 21 & 0.002 & -0.018 & 0.467 & 0.001 & $\mathrm{~S}$ \\
\hline Oystercatcher (D) & Mytilus edulis & Exe estuary, England & J. D. Goss-Custard, S. Durell \& A. D. West & 20 & 0.052 & 0.293 & 0.184 & 0.069 & C \\
\hline Oystercatcher (V) & Mytilus edulis & Exe estuary, England & J. D. Goss-Custard, S. Durell \& A. D. West & 13 & $<0.001$ & 0.023 & 0.699 & 0.001 & $\mathrm{~L}$ \\
\hline Oystercatcher (V) & Mytilus edulis & Ythan estuary, Scotland & P. U. U. Fernando & 30 & $<0.001$ & -0.101 & 0.503 & $<0.001$ & $\mathrm{C}$ \\
\hline Curlew & Hediste diversicolor & Exe estuary, England & J. D. Goss-Custard \& A. D. West & 20 & $<0.001$ & 0.462 & 0.573 & $<0.001$ & C \\
\hline Curlew & Scrobicularia plana & Exe estuary, England & J. D. Goss-Custard \& A. D. West & 10 & 0.058 & 0.077 & 0.399 & 0.070 & $\mathrm{C}$ \\
\hline Eastern curlew & Trypaea australiensis & Moreton Bay, Australia & Y. Zharikov & 12 & 0.016 & 0.179 & 0.649 & 0.004 & $\mathrm{~L}$ \\
\hline
\end{tabular}


Table 3. Parameters of the functional response in shorebirds. In most cases, asymptotes and half-asymptote constants were calculated using the hyperbolic asymptotic function of intake rate against numerical prey density. Where the data range and/or sample size were inadequate, the mean value of the available data provides an estimate of the asymptote only. The mean size of the prey consumed by the birds across all the data for each response is shown in parentheses (mgAFDM). In oystercatchers, S mean they fed by stabbing and $\mathrm{H}$ means they fed by hammering, with $\mathrm{D}$ and $\mathrm{V}$ meaning that the birds hammered into the shell on the dorsal and ventral sides, respectively.

\begin{tabular}{|c|c|c|c|c|c|c|c|c|}
\hline Bird & Prey (mean mgAFDM) & Study area & Source of data & $\mathcal{N}$ & $\begin{array}{l}\text { Asymptote } \\
\left(\mathrm{mgAFDMs}^{-1}\right)\end{array}$ & S.E.M. & $\begin{array}{l}\text { Half- } \\
\text { asymptote } \\
\text { constant } \\
\left(\text { prey } / \mathrm{m}^{-1}\right)\end{array}$ & S.E.M. \\
\hline Gurlew sandpiper & Ceratonereis spp. (3.042) & Berg estuary, South Africa & B. Kalejta-Summers & 37 & 0.220 & 0.025 & $<1.0$ & 260.0 \\
\hline Knot & Cerastoderma edule (1.990) & Wash, England & M. G. Yates \& J. D. Goss-Custard & 21 & 0.183 & 0.022 & 17.3 & 79.8 \\
\hline Redshank & Corophium volutator (0.697) & Estuaries in SW, England & J. D. Goss-Custard & 9 & 0.317 & 0.022 & 55.6 & 36.8 \\
\hline Redshank & Corophium volutator (0.639) & Ythan estuary, Scotland & J. D. Goss-Custard & Mean 4 & 0.588 & 0.019 & - & - \\
\hline Redshank & Corophium volutator (0.426) & Ythan estuary, Scotland & J. D. Goss-Custard & Mean 10 & 0.416 & 0.019 & - & - \\
\hline Redshank & Hediste diversicolor (28.14) & Estuaries in SW, England & J. D. Goss-Custard & 6 & 0.563 & 0.188 & $<1.0$ & - \\
\hline Redshank & Hediste diversicolor (6.26) & Estuaries in SW, England & J. D. Goss-Custard & 11 & 0.344 & 0.092 & 46.1 & 129.3 \\
\hline Grey plover & Ceratonereis spp. (7.781) & Berg estuary, South Africa & B. Kalejta-Summers & 25 & 0.555 & 0.095 & 38.1 & 495.0 \\
\hline Black-tailed godwit & Bivalva (4.813) & Estuaries in SE England & J. A. Gill & 11 & 0.621 & 0.169 & 170.5 & 155.1 \\
\hline Black-tailed godwit & Bivalva (1.507) & Estuaries in SE England & J. A. Gill & 28 & 0.350 & 0.071 & 809.6 & 371.6 \\
\hline Black-tailed godwit & Scrobicularia plana (13.65) & Exe estuary, England & J. D. Goss-Custard \& A. D. West & Mean 10 & 0.679 & 0.093 & - & - \\
\hline Black-tailed godwit & Lumbricidae $(6.800)$ & Southern England & J. A. Gill & Mean 5 & 0.542 & 0.067 & - & - \\
\hline Oystercatcher & Macoma balthica (92.63) & Wadden Sea, Netherlands & B. J. Ens & 24 & 3.117 & 0.497 & 63.9 & 32.2 \\
\hline Oystercatcher & Scrobicularia plana (105.5) & Exe estuary, England & J. D. Goss-Custard \& A. D. West & 17 & 2.011 & 0.220 & 1.3 & 2.8 \\
\hline Oystercatcher & Hediste diversicolor (29.05) & Exe estuary, England & J. D. Goss-Custard \& A. D. West & 10 & 1.486 & 0.343 & 29.6 & 58.1 \\
\hline Oystercatcher $(\mathrm{S})$ & Cerastoderma edule (460.4) & Wadden Sea, Netherlands & B. J. Ens & 115 & 2.955 & 0.201 & 1.0 & 1.1 \\
\hline Oystercatcher $(\mathrm{H})$ & Cerastoderma edule (114.2) & Burry Inlet, Wales & I. Johnstone & 9 & 2.193 & 0.525 & 62.6 & 72.4 \\
\hline Oystercatcher $(\mathrm{H})$ & Cerastoderma edule (42.43) & Burry Inlet, Wales & I. Johnstone & 15 & 1.658 & 0.364 & 62.7 & 75.5 \\
\hline Oystercatcher (S) & Cerastoderma edule (156.7) & Baie de Somme, France & P. Triplet & 9 & 1.810 & 0.295 & 54.5 & 50.8 \\
\hline Oystercatcher (S) & Cerastoderma edule (211.2) & Traeth Melynogg, Wales & W.J. Sutherland & 12 & 2.119 & 0.232 & 0.8 & 2.8 \\
\hline Oystercatcher (S) & Mytilus edulis (471.6) & Exe estuary, England & J. D. Goss-Custard, S. Durell \& A. D. West & 21 & 1.612 & 0.069 & $<1.0$ & 4.8 \\
\hline Oystercatcher (D) & Mytilus edulis (578.2) & Exe estuary, England & J. D. Goss-Custard, S. Durell \& A. D. West & 20 & 2.375 & 0.120 & 10.9 & 9.0 \\
\hline Oystercatcher $(\mathrm{V})$ & Mytilus edulis (577.5) & Exe estuary, England & J. D. Goss-Custard, S. Durell \& A. D. West & 13 & 1.985 & 0.134 & $<1.0$ & 2.6 \\
\hline Oystercatcher $(\mathrm{V})$ & Mytilus edulis (147.3) & Ythan estuary, Scotland & P. U. U. Fernando & 30 & 1.574 & 0.179 & 10.6 & 18.0 \\
\hline Gurlew & Hediste diversicolor (37.59) & Exe estuary, England & J. D. Goss-Custard \& A. D. West & 15 & 1.091 & 0.151 & $<1.0$ & 16.3 \\
\hline Curlew & Hediste diversicolor (16.35) & Exe estuary, England & J. D. Goss-Custard \& A. D. West & Mean 5 & 0.461 & 0.087 & - & - \\
\hline Curlew & Hediste diversicolor (64.8) & Wadden Sea, Netherlands & L. Zwarts & 9 & 1.812 & 0.281 & 6.0 & 9.7 \\
\hline Curlew & Scrobicularia plana (94.6) & Exe estuary, England & J. D. Goss-Custard \& A. D. West & 10 & 2.210 & 0.620 & 14.9 & 23.5 \\
\hline Curlew & Arenicola marina (121.6) & Wadden Sea, Netherlands & L. Zwarts & Mean 5 & 2.595 & 0.073 & - & - \\
\hline Eastern curlew & Trypaea australiensis (34.71) & Moreton Bay, Australia & Y. Zharikov & Mean 11 & 0.804 & 0.074 & - & - \\
\hline
\end{tabular}


Table 4. The proportion of time while foraging at the asymptote of the functional responses that shorebirds spend on handling prey, including waste handling time and unsuccessful pecks and probes. The remaining time was spent walking with head aloft, the birds apparently searching visually for prey. $\mathcal{N}$ refers to the number of separate sites from which the data were obtained. For oystercatchers S means that they fed by stabbing, while D and V mean that birds hammered into the dorsal and ventral sides of the shell, respectively.

\begin{tabular}{|c|c|c|c|c|c|c|}
\hline \multirow[b]{2}{*}{ Bird } & \multirow[b]{2}{*}{ Prey species } & \multirow[b]{2}{*}{ Site } & \multicolumn{3}{|c|}{$\begin{array}{l}\text { Percentage } \\
\text { of time spent } \\
\text { dealing with } \\
\text { prey, whether } \\
\text { successfully } \\
\text { or not }\end{array}$} & \multirow[b]{2}{*}{ Source } \\
\hline & & & $\%$ & S.E.M. & $\mathcal{N}$ & \\
\hline Redshank & Corophium volutator & SW England & 40.5 & 2.88 & 8 & Goss-Custard (1977d) \\
\hline Redshank & Corophium volutator & Ythan estuary & 78.4 & 3.22 & 6 & Goss-Custard (1970) \\
\hline Redshank & large Hediste diversicolor & SW England & 28.0 & 2.08 & 17 & Goss-Custard $(1977 b)$ \\
\hline Black-tailed godwit & Scrobicularia plana & Exe estuary & 54.0 & 9.90 & 6 & J. D. Goss-Custard \& A. D. West, present study \\
\hline Oystercatcher & Scrobicularia plana & Exe estuary & 49.6 & 6.71 & 8 & J. D. Goss-Custard \& A. D. West, present study \\
\hline Oystercatcher & Hediste diversicolor & Exe estuary & 34.3 & 2.65 & 8 & J. D. Goss-Custard \& A. D. West, present study \\
\hline Oystercatcher (S) & Mytilus edulis & Exe estuary & 56.3 & 2.15 & 21 & J. D. Goss-Custard et al. (2001) \\
\hline Oystercatcher (D) & Mytilus edulis & Exe estuary & 68.1 & 3.20 & 20 & Goss-Custard et al. (2001) \\
\hline Oystercatcher (V) & Mytilus edulis & Exe estuary & 66.5 & 2.93 & 13 & Goss-Custard et al. (2001) \\
\hline Curlew & large Hediste diversicolor & Exe estuary & 38.8 & 10.10 & 8 & J. D. Goss-Custard \& A. D. West, present study \\
\hline Curlew & large Scrobicularia plana & Exe estuary & 50.8 & 10.60 & 7 & J. D. Goss-Custard \& A. D. West, present study \\
\hline
\end{tabular}

The correlation between observed and predicted asymptotes from the two-variable (body mass and prey mass) model (open circles in Fig. 2) was also close. On average, it under-predicted observed asymptotes by $6.6 \%$ (range $-166.6 \%$ to $+57.5 \%, \mathcal{N}=30$ ) but, as the S.E.M. was $8.7 \%$, the mean discrepancy was again not significantly different from zero. With the two Ythan redshank points excluded, the observed asymptotes were on average only $3.0 \%$ (S.E.M. $=5.8$; range $-86.2 \%$ to $+57.5 \% ; \mathcal{N}=28$ ) higher than predicted.

The slightly poorer performance of this two-variable model was due to five values (double circles in Fig. 2) from the one study of breeding birds (oystercatchers eating Macoma balthica in the Wadden Sea) and the four of oystercatchers eating mussels. Without these five points, the observed-predicted regression line had an intercept of -0.027 (S.E.M. =0.104) and a slope of 1.057 (S.E.M. = 0.078), not significantly different from zero or unity, respectively. The average deviation of the observed asymptotes from the predicted values was $-9.1 \%$ (S.E.M.= $9.5 \%$; range $-166.6 \%$ to $+57.5 \% ; \mathcal{N}=25)$, with the Ythan redshank included, but only $2.3 \%$ (S.E.M. $5.4 \%$; range $-40.0 \%$ to $+57.5 \% ; \mathcal{N}=23$ ) with these two cases excluded. Thus, on average, it made little difference to the comparison between observed and predicted asymptotes whether the five data points on breeding birds and oystercatchers eating mussels were included. But it made a large difference to the precision of the predictions for birds in these two categories (Fig. 2). The two-variable model could lead to large under-predictions of the asymptote in breeding shorebirds (here $-86 \%$ ) or to large over-predictions in oystercatchers eating mussels $(+19.1 \%$ to $+43.1 \%$ here $)$.
For such birds, the four-variable model would give better predictions.

\section{(b) Half-asymptote constant}

A step-down multiple regression of the half-asymptote constants in Table 3 used a limited number of independent variables because of the small sample size $(\mathcal{N}=23)$; bird and prey masses, prey taxon and whether the bird was an oystercatcher or breeding. As the two values from blacktailed godwits in SE England were so exceptionally high (Table 3), they were represented by a dummy $0 / 1$ variable, in case they had undue influence.

In fact, the only overall significant variable selected with untransformed data was this dummy variable (adj $\left.R^{2}=63.1 \%, P<0.001\right)$. With these two data omitted, the only overall significant regression $\left(\operatorname{adj} R^{2}=23.3 \%\right.$, $P=0.036$ ) was obtained with prey mass (coefficient $=0.087$, S.E.M. $=0.031, P=0.012)$, and the dummy variable representing oystercatchers as 1 (coefficient $=24.25$, S.E.M. $=$ 11.86, $P=0.056$ ). With the half-asymptote constant, body mass and prey mass all transformed to logarithms, the only overall significant regression $\left(\operatorname{adj} R^{2}=27.5 \%, P=0.028\right.$ ) for $\log _{\mathrm{e}}$ half-asymptote constant was with $\log _{\mathrm{e}}$ body mass (coefficient $=6.307$, S.E.M. $=3.224, P=0.065)$, $\log _{\mathrm{e}}$ prey mass $($ coefficient $=5.030$, S.E.M. $=1.495, P=0.003)$, and the dummy variable representing oystercatchers as 1 (coefficient $=10.594$, S.E.M. $=4.699, P=0.036)$. The intercept was -24.77 (S.E.M. $=15.84, P=0.134$ ) and the error mean square was 52.47 .

Although sample size was small, the results suggest that half the asymptotic intake rate was reached at higher 
Table 5. Multiple regression analysis of the correlates of $\log _{\mathrm{e}}$ intake rates in shorebirds. $P$-value is the significance of the difference of the coefficient from zero. A dash $(-)$ means the variable was not selected. An asterisk $\left(^{*}\right)$ means that the variable was not included in the analysis. EMS is the Error Mean Square, sometimes known as Residual Mean Square.

\begin{tabular}{|c|c|c|c|c|c|c|c|c|c|c|c|c|c|c|c|c|c|c|}
\hline \multirow[b]{2}{*}{ Variable } & \multicolumn{3}{|c|}{$\begin{array}{l}\text { Shorebirds excluding } \\
\text { Oystercatchers }\end{array}$} & \multicolumn{3}{|c|}{$\begin{array}{l}\text { Oystercatchers eating } \\
\text { non-armoured prey }\end{array}$} & \multicolumn{3}{|c|}{$\begin{array}{l}\text { Shorebirds including } \\
\text { oystercatchers eating } \\
\text { non-armoured prey }\end{array}$} & \multicolumn{3}{|c|}{$\begin{array}{l}\text { All data including } \\
\text { oystercatchers eating } \\
\text { armoured and } \\
\text { non-armoured prey }\end{array}$} & \multicolumn{3}{|c|}{$\begin{array}{l}\text { All data but reduced } \\
\text { variables }\end{array}$} & \multicolumn{3}{|c|}{$\begin{array}{l}\text { All data but only two } \\
\text { variable model }\end{array}$} \\
\hline & $\begin{array}{l}\text { Coeffi- } \\
\text { cient }\end{array}$ & S.E.M. & $(P$-value $)$ & $\begin{array}{l}\text { Coeffi- } \\
\text { cient }\end{array}$ & S.E.M. & $(P$-value $)$ & $\begin{array}{l}\text { Coeffi- } \\
\text { cient }\end{array}$ & S.E.M. & $(P$-value $)$ & $\begin{array}{l}\text { Coeffi- } \\
\text { cient }\end{array}$ & S.E.M. & $(P$-value $)$ & $\begin{array}{l}\text { Coeffi- } \\
\text { cient }\end{array}$ & S.E.M. & $(P$-value $)$ & $\begin{array}{l}\text { Coeffi- } \\
\text { cient }\end{array}$ & S.E.M. & ( $P$-value $)$ \\
\hline Constant & -2.287 & 0.291 & $(<0.001)$ & -2.042 & 0.226 & $(<0.001)$ & -2.406 & 0.275 & $(<0.001)$ & -2.457 & 0.234 & $(<0.001)$ & -2.802 & 0.192 & $(<0.001)$ & -2.977 & 0.197 & $(<0.001)$ \\
\hline $\log _{e}$ body mass $(\mathrm{g})$ & 0.353 & 0.054 & $(<0.001)$ & $*$ & & & 0.156 & 0.062 & $(0.013)$ & 0.168 & 0.051 & $(0.001)$ & 0.245 & 0.043 & $(<0.001)$ & 0.303 & 0.043 & $(<0.001)$ \\
\hline $\begin{array}{l}\text { Log }_{\text {e }} \text { prey mass } \\
\text { (mgAFDM) }\end{array}$ & 0.437 & 0.031 & $(<0.001)$ & 0.674 & 0.048 & $(<0.001)$ & 0.119 & 0.101 & $(0.239)$ & 0.128 & 0.093 & $(0.168)$ & 0.365 & 0.020 & $(<0.001)$ & 0.323 & 0.019 & $(<0.001)$ \\
\hline Interaction & - & & & $*$ & & & 0.057 & 0.019 & $(0.002)$ & 0.055 & 0.016 & $(0.001)$ & * & & & * & & \\
\hline Polychaete $=1$ & - & & & 0.295 & 0.095 & $(0.003)$ & - & - & & - & & & * & & & $*$ & & \\
\hline Mollusc $=1$ & -0.771 & 0.133 & $(<0.001)$ & - & & & -0.178 & 0.075 & $(0.018)$ & -0.182 & 0.066 & $(0.006)$ & * & & & $*$ & & \\
\hline Crustacean $=1$ & -0.736 & 0.103 & $(<0.001)$ & $*$ & & & -0.526 & 0.089 & $(<0.001)$ & -0.526 & 0.084 & $(<0.001)$ & * & & & * & & \\
\hline Insect $=1$ & - & & & - & & & - & & & - & & & * & & & * & & \\
\hline Earthworm = 1 & - & & & - & & & -0.367 & 0.153 & $(0.017)$ & -0.368 & 0.144 & $(0.011)$ & * & & & * & & \\
\hline Brine shrimp $=1$ & 1.216 & 0.190 & $(<0.001)$ & $*$ & & & 1.122 & 0.197 & $(<0.001)$ & 1.121 & 0.184 & $(<0.001)$ & * & & & * & & \\
\hline $\begin{array}{l}\text { Surface-living } \\
\text { prey }=1\end{array}$ & 0.530 & 0.179 & $(0.004)$ & -0.533 & 0.129 & $(<0.001)$ & - & & & - & & & $*$ & & & * & & \\
\hline $\begin{array}{l}\text { Prey can retreat } \\
\text { into burrow }=1\end{array}$ & -0.258 & 0.101 & $(0.012)$ & - & & & - & & & - & & & & & & * & & \\
\hline Oystercatcher $=1$ & $*$ & & & $*$ & & & -0.189 & 0.090 & $(0.036)$ & -0.205 & 0.080 & $(0.011)$ & $*$ & & & * & & \\
\hline $\begin{array}{l}\text { Oystercatcher } \\
\text { eating mussels }=1\end{array}$ & $*$ & & & $*$ & & & * & & & -0.320 & 0.073 & $(<0.001)$ & -0.227 & 0.070 & $(0.001)$ & $*$ & & \\
\hline $\begin{array}{l}\text { Detect prey } \\
\text { visually }=1\end{array}$ & - & & & -0.557 & 0.117 & $(<0.001)$ & - & & & - & & & $*$ & & & * & & \\
\hline Breeding $=1$ & 0.434 & 0.174 & $(0.013)$ & 0.192 & 0.086 & $(0.027)$ & 0.380 & 0.090 & $(<0.001)$ & 0.417 & 0.074 & $(<0.001)$ & 0.379 & 0.077 & $(<0.001)$ & * & & \\
\hline $\begin{array}{l}\text { Plover search } \\
\text { strategy }=1\end{array}$ & -0.222 & 0.090 & $(0.014)$ & $*$ & & & - & & & - & & & $*$ & & & * & & \\
\hline $\begin{array}{l}\text { Minutes } \mathrm{N} \text { or } \mathrm{S} \\
\text { of equator }\end{array}$ & -0.000296 & 0.000079 & $(<0.001)$ & $*$ & & & - & & & - & & & $*$ & & & * & & \\
\hline $\mathcal{N}$ & 208 & & & 108 & & & 316 & & & 468 & & & 468 & & & 468 & & \\
\hline Adj. $R^{2}(\%)$ & 79.0 & & & 68.0 & & & 79.7 & & & 81.0 & & & 77.3 & & & 75.5 & & \\
\hline$P$ & $<0.001$ & & & $<0.001$ & & & $<0.001$ & & & $<0.001$ & & & $<0.001$ & & & $<0.001$ & & \\
\hline EMS & 0.230 & & & 0.158 & & & 0.251 & & & 0.222 & & & 0.270 & & & 0.290 & & \\
\hline
\end{tabular}




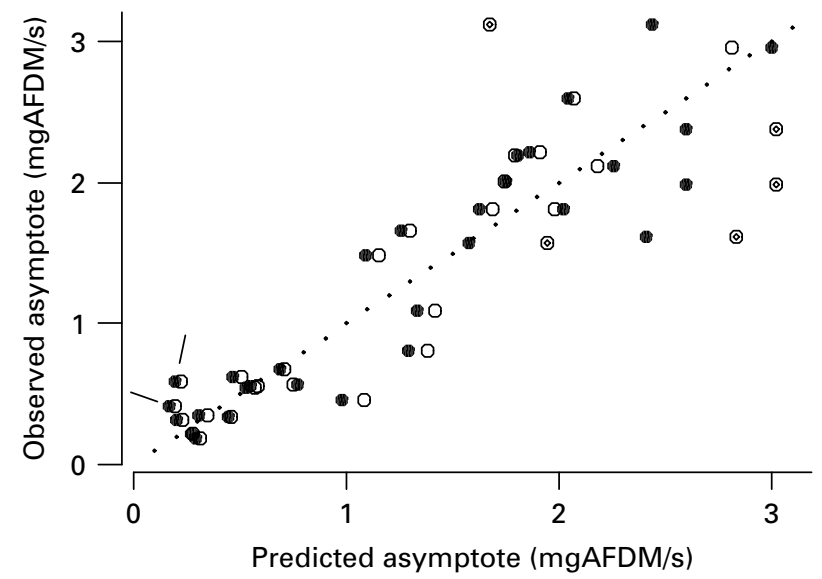

Fig. 2. The observed asymptotes of the functional responses given in Table 2 in relation to the predicted asymptotes from the four-variable and two-variable equations shown in the last two columns of Table 5. Filled circles: equation including body mass, prey mass and whether the bird was an oystercatcher eating mussels or breeding. Open circles: equation only includes body mass and prey mass; the double circles show breeding birds or oystercatchers eating mussels. The two short lines indicate the two studies on redshank eating Corophium volutator on the Ythan estuary. Dotted line shows $Y=X$. AFDM, ash-free dry mass.

prey densities when both the prey and birds were large, and especially if they were oystercatchers. That is, the gradient was more steep when the prey were small and less steep in large birds, especially oystercatchers. The predictive ability of the equation cannot be tested until the parameters from more functional responses become available.

\section{DISGUSSION}

\section{(1) Phylogenetic effects}

There has been considerable debate in the literature concerning the circumstances under which it is valid to use raw species-specific data in comparative analyses, versus the circumstances in which it is prudent to take phylogenetic relationships into account (Harvey \& Pagel, 1991; Price, 1997; Harvey \& Rambaut, 2000; Bennett \& Owens, 2002; Freckleton, Harvey \& Pagel, 2002). In this study, where we test for associations between traits across relatively distantly-related species that are not members of a single adaptive radiation, the potential danger of using raw species-specific data is that any associations may be due to common ancestry rather than convergent evolution (Bennett \& Owens, 2002). If this were the case, such phylogenetic non-independence could invalidate any implied causal basis to the identified relationships.

We confirmed the robustness of the analyses we have presented in the Results by using two further independent analytical techniques on the same data. In the first instance we used GLMMs as described in the Methods section.
Here, a hierarchical model was used with genus coded as Level 3, species as Level 2, and observation as Level 1. Partitioning the variance in $\log _{\mathrm{e}}$ intake rate revealed that $44.9 \%$ of the variance lay at the between-genus level, $19.2 \%$ at the between-species level, and the remainder $(35.9 \%)$ at the between-observation level. Adding $\log _{\mathrm{e}}$ body mass as a fixed effect reduced the variance attributable to the between-genus level from $0.520( \pm 0.313)$ to zero $(<0.001 \pm<0.001)$, the values in parentheses again being the S.E.M.s. The variances from the second and first levels were reduced from $0.222( \pm 0.113)$ to $0.131( \pm 0.056)$ [Level 2] and $0.416( \pm 0.028)$ to $0.413( \pm 0.028)$ [Level 1]. Independently, adding $\log _{\mathrm{e}}$ prey mass as a fixed effect again strongly reduced the between genus variance to being not significantly different from zero $(0.014 \pm 0.042)$, and resulted in nearly halving the between-species variance to $0.135( \pm 0.062)$. The Level 1 variance was also considerably reduced to $0.246( \pm 0.017)$. In other words, much of the variance attributable to differences between observations in intake rate can be considerably reduced by incorporating life-history trait (body mass) and prey size. This helps to explain the high coefficient of determination that we were able to demonstrate in our simple two-variable model in Table 5, in which the addition of prey mass and body mass explained $75.5 \%$ of the GLM model variance in intake rates.

In order to test whether the results in Table 5 could be an artefact of phylogenetic relationships, the analyses were repeated using the independent contrasts method to control for the confounding effects of common ancestry (Felsenstein, 1985; Harvey \& Pagel, 1991; Pagel, 1992), with contrasts being calculated using the CAIC program (Purvis \& Rambaut, 1995). The molecular phylogenies of Paton et al. (2003) and Thomas, Wills \& Szekely (2004) were used to construct a composite bifurcating phylogeny of the species in the analyses, with all branch lengths set to the same length. Linear least-squares regression models were then used to test for associations between contrasts in intake rate and contrasts in both body size and prey size. All regression models were forced through the origin (Pagel, 1992).

These analyses based on phylogenetically independent contrasts largely supported the other analyses based on species-specific values. Both univariate and multivariate models confirmed that there were significant positive associations between intake rate and both body size and prey size. Also, the multivariate models based on phylogenetic contrasts were qualitatively the same as those based on using each population as an independent data point. These findings confirm that the key relationships described here are not due to the phylogenetic pattern of relationships among the species concerned.

\section{(2) Causal basis of the correlates of intake rate}

That large birds eating large prey generally had the highest intake rates was expected because of the well-established allometric relationship between intake rate and body mass in birds (Bryant \& Westerterp, 1980; Zwarts, Blomert \& Hupkes, 1990) and the generally greater profitability 
of large prey items and the ability of large birds to consume them (Zwarts \& Blomert, 1992). The causal basis of the associations between intake rate and some other statistically significant predictor variables is more uncertain, however. It is unclear why, taking bird and prey sizes into account, intake rates were consistently lower in birds eating molluscs, crustaceans and earthworms and higher in birds eating Artemia. Differences between prey taxa in availability to shorebirds or in their anti-predator defence mechanisms might be responsible; for example, Artemia shows no obvious anti-predator responses and is highly visible as it swarms in the water. It is unclear why intake rates were sometimes lower in birds using a plover searching method, or in birds feeding further from the equator or in oystercatchers detecting prey visually. Of course, some associations may have no causal basis, as might be implied by the selection of 'Surface-living prey $=1$ ' where the sign differed between oystercatchers and other shorebirds.

The causal basis of the remaining associations may be more clear. Breeding birds consistently had higher intake rates than non-breeders. Prey availability may be higher in the breeding season if prey are more active in warmer sediments or take greater risks when foraging to prepare for reproduction (Ens, Klaassen \& Zwarts, 1993). Alternatively, the priorities of birds themselves may change from reducing their risk of being attacked by predators while foraging (Cresswell, 1994), or of damaging their bill (Swennen, Leopold \& de Bruijn, 1989) or consuming parasites (Norris, 1999) to meeting the increased energy demands due to breeding with an associated increase in gut processing rate. Oystercatchers generally had lower intake rates than other shorebirds, taking prey and bird size into account, perhaps because many of their prey are heavily-armoured (Zwarts et al., 1996). Oystercatchers in captivity fed even more slowly, perhaps because of reduced food demand and consequent lower gut processing rate or because captivity affected their foraging behaviour or they were given prey to which they were not specialised.

The reduced intake rate in shorebirds eating prey that could retreat into a burrow may imply that this antipredator behaviour is effective in reducing intake rate in shorebirds, and also introduces the possibility that interference through prey depression may have occurred in our sample (Yates, Stillman \& Goss-Custard, 2000). Interference from intra-specific and inter-specific kleptoparasitism may also have occurred. Excluding oystercatchers eating mussels or cockles in which interference through intra-specific kleptoparasitism does occur (Stillman, GossCustard \& Caldow, 1997; Triplet, Stillman \& GossCustard, 1999; but see Norris \& Johnstone, 1998a), intraspecific and/or interspecifc interactions were noted in one third of the studies of intake rates across 18 species. As some authors did not record whether such interactions occurred, this is likely to be a minimum estimate. However, the magnitude of any interference effect cannot be determined without very careful study (Goss-Custard, 2003), especially as recent studies suggest that sometimes shorebirds are able to minimise its effect (van Gils \& Piersma, 2004).

\section{(3) What determines the asymptote?}

Jeschke et al. (2002) and Whelan \& Brown (2005) adapted the Holling type II disc equation model so that the asymptote can be determined by the gut processing rate as well as by handling time. In all 11 studies of four species reported here, the asymptote of the instantaneous intake rate functional response was not set by handling time because only about half the foraging time was spent handling prey or in pecking or probing unsuccessfully at unknown cues. The remaining time was spent searching. The present study also found that the asymptote can differ by as much as twofold between studies of the same bird species eating the same prey species (Table 3). However, this finding cannot be taken necessarily to imply that gut capacity and processing rate were generally not limiting the asymptote. For example, in the model of Jeschke et al. (2002), the fullness of the gut determines the satiation level. This in turn affects the predator's hunting efficiency which is assumed to decline linearly with satiation. The asymptote may therefore vary according to the birds' degree of satiation, which itself may vary between locations and times of the year.

In our study, this idea could be explored only by testing whether intake rate increased through the autumn and winter as the birds' demand for food would have increased, as had previously been found in oystercatchers (GossCustard et al., 2001). In fact, in a multiple regression in which prey size and prey density were also included, intake rate did not increase significantly with the number of days elapsed since August 1st in any of the studies of oystercatchers and curlews on the Exe estuary. Although in oystercatchers and curlews eating clams and ragworms an increasing hunger may have been counterbalanced by declining prey availability associated with decreasing ambient temperature, this would not have applied in oystercatchers eating mussels lying fully exposed on the sediment surface.

Finding that the gut capacity and processing rate did not apparently account for the asymptote in oystercatchers eating mussels, Goss-Custard et al. (2001) resurrected Holling's (1959) idea that, in addition to observable handling time, there might be an unobservable perceptual time cost associated with detecting prey which, in combination with handling time, limited the rate of feeding, and thus the asymptotic intake rate. This is similar to the suggestion of Mitchell \& Brown (1990) that the maximum asymptote set by handling time may not be reached because other vital activities must also be carried out which cost time and which therefore depress intake rate below its potential maximum. The present study has not tested these ideas further. However, the asymptotes of the functional responses of turnstone Arenaria interpres eating more-or-less identical cereal grains lying clearly visible on a solid surface (Smart \& Gill, 2003) and knot Calidris canutus eating the more-or-less identical eggs of horseshoe crabs Limulus polyphemus lying clearly visible on the sediment were, respectively, 19 and 15 times higher than would be predicted by the equations given in Table 5 (R. A. Stillman and S. Gillings, unpublished data). These observations are consistent with 
the idea that perceptual constraints may contribute to determining the asymptotes of shorebirds eating macroinvertebrate prey that are not only difficult to detect but amongst which a selection has to be made.

\section{(4) Predicting the coefficients of the functional response}

As the asymptote was not set by handling time, as the parameters required to predict the maximum intake rate from a bird's satiation level are unknown, and as the possible role of perceptual time constraints on intake rate remains speculative, shorebird asymptotes cannot yet be predicted from theoretically-based process models of the functional response. However, the review of shorebird functional responses revealed that intake rate varied independently of the numerical density of the prey over a wide range and that the asymptote was usually reached at very low prey densities $\left(<150 / \mathrm{m}^{-2}\right)$ compared with the densities of prey that typically occur; the only exceptions came from one study of black-tailed godwits eating small bivalve molluscs in east England (Gill et al., 2001). Therefore most of the spot estimates of intake rate were probably obtained at or near to the asymptote of the functional response, raising the possibility that correlates of these spot estimates could predict the asymptote.

The multivariate analysis of the 468 spot estimates of intake rates from 26 species of 11 genera identified ten variables representing natural history features of the prey and shorebird that accounted for $81 \%$ of the variance in logarithm-transformed intake rates. However, just four variables accounted for almost as much (77.3\%), the variables being bird size (body mass), prey size (mean mass of the prey consumed), whether the bird was an oystercatcher eating mussels and whether it was breeding. Given the large number of different workers involved in obtaining the data, the variety of methods used and the range of species and situations from which the estimates of intake were obtained, it is quite astonishing that so few variables were able to account for so much of the variance in intake rates.

This four-variable model under-predicted the observed asymptote across all 30 estimates by an average of $11.6 \%$ but the discrepancy was only $0.2 \%$ when two suspect estimates were removed. This model therefore predicted the observed asymptote successfully in $93 \%$ of cases. A twovariable model that included only bird mass and prey mass predicted the asymptotes with almost equal precision, suggesting that often one only needs to know these two very easily acquired parameters. However, this model gave poor predictions for breeding shorebirds and for oystercatchers eating mussels, for which the four-variable model should be used. Nonetheless, it was a gratifying surprise that so simple an equation could predict so well the asymptote of the functional response that, using conventional field studies, can take many months or years to establish.

A multivariate analysis of the 23 estimates of the halfasymptote constant suggested that half the asymptotic intake rate was reached at lower prey densities when the prey were small but, taking prey size into account, this occurred at higher prey densities when the birds were large, especially if they were oystercatchers. The resulting equation could be used to predict the half-asymptote constant of the functional response, but its predictive power has yet to be tested. It is concluded that the asymptote of the functional response in shorebirds can be reliably predicted from just four easily measured variables, and that future work may confirm that the half-asymptote constants may also be predicted this way.

\section{(5) Utility of the predictive equations}

The study reported herein was undertaken to try to establish a means by which the parameters of the functional response could be estimated so that they could be used in individualbased models (IBMs) - that are also behaviour-based - of shorebird populations of many species (Goss-Custard \& Stillman, in press). Individual-based models are increasingly being used to solve applied ecological questions to which conventional ecological procedures fail to provide the answers (Grimm \& Railsbeck, 2005). As a result of the findings reported in this paper, the shorebird IBM can now be applied to a very wide range of practical issues across many shorebird species and systems throughout the World (Goss-Custard \& Stillman, in press).

For the particular purpose of parameterising the shorebird IBM, the uncertainty about the confidence with which one coefficient of the functional response, the halfasymptote constant, can at present be predicted in shorebirds does not, however, diminish the usefulness of being able to predict the other, the asymptote. This is because most of the field studies show that the half-asymptote constant takes generally low values in shorebirds and, for many purposes, using a mean estimate obtained across all studies will suffice. The numerical densities of the prey of shorebirds are generally exceedingly high, as the range of prey densities shown in Fig. 1 illustrates. The variation in the half-asymptote constants is therefore very small compared with the range of prey densities that naturally occur. In addition, prey depletion by shorebirds is often the principal cause of mortality of their prey but seldom exceeds $50 \%$ of the initial stocks (Goss-Custard, 1980) or annual production of the prey (van der Meer, Piersma \& Beukema, 2001), and is usually much less. In view of the typically very high numerical densities of shorebird prey, their food stocks seem seldom to be reduced to the level at which intake rate begins to fall. The factor that most affects fitness is not the numerical density but the size (mgAFDM), or food value, of the average food item and, perhaps, whether interference between foraging birds is strong or weak. In the one example so far available, the decrease in prey mass over the winter in combination with strong interference caused the observed density-dependent winter mortality in oystercatchers eating mussels: prey depletion played no role at all in determining bird fitness (GossCustard et al., 2001). Of course, it remains to be seen how generally applicable this finding might be but the confirmation in this paper that prey size rather than numerical prey density determines intake rate in shorebirds is in line with this result. On present evidence, therefore, the more 
important parameter to be able to predict easily is the asymptote, and not the gradient as conventional wisdom assumes.

Even though the predictive equations presented above were encouragingly good at predicting the observed asymptotes, it would be wise for nature managers and their scientific advisors to take into account the wide confidence limits around a single prediction by running sensitivity analyses whenever the equations are applied to a particular case.

As mentioned earlier, many studies of shorebirds only need to estimate intake rate and do not need to relate intake rate to prey density. The equations developed here should enable research workers engaged in many areas of shorebird ecology and behaviour to estimate intake rate without the need for conventional time-consuming field studies, even when these are practicable: in many shorebirds, - especially the small-sized ones eating small prey - methods have not yet been devised for measuring intake rate in the field. It is very easy to measure mean prey size expressed in mgAFDM from (i) the size (maximum length or width) frequency histogram of the prey in the location being studied, and (ii) allometric equations between prey size and AFDM, using the procedure detailed in Goss-Custard et al. (2002). The rest of the information needed to apply the equations, such as bird mass, is readily available. It is hoped that the equations will provide a useful stimulus to studies of shorebird ecology and behaviour across a wide range of issues including not only IBMs but also predatorprey interactions, foraging theory, the quality of feeding grounds (measured in terms of potential intake rate), the trade-off between consuming food and other factors that may affect fitness, such as the risk of being taken by a predator, and food-related reproductive success. We also hope that more workers on other animal groups might be stimulated by these findings from shorebirds to try to establish similar equations for other vertebrate taxa, as has previously been achieved for ungulates (Shipley et al., 1994).

\section{GONGLUSIONS}

(1) The results provide confirmation that, in shorebirds eating macro-invertebrates, (i) the general form of the functional response - the function relating intake rate to prey density - is captured by the Holling type II ('disc equation') response of a decelerating rise to an asymptote, but (ii) that the asymptote of the response is not set by handling time, as is assumed by the widely used disc equation.

(2) The factors and processes that determine the asymptote of the functional response in shorebirds are unknown. Further theoretical and empirical research is needed to fill this gap in our understanding.

(3) Until this has been achieved, it would be very useful for parameterising IBMs of shorebird populations to be able to predict the parameters of the functional response from a small number of easily obtained quantities.
(4) A review of 30 functional responses of shorebirds showed that, in most cases, intake rate levels off at the asymptote at rather low numerical densities of the prey. This means that most of the many studies of intake rate in shorebirds have probably been carried out at or near the asymptote of the functional response. This in turn means that equations that predict intake rate should also predict the asymptote of the functional response.

(5) A multivariate analysis of 468 spot estimates of intake from 26 species of shorebirds showed that only four variables accounted for $77.3 \%$ of the variance in logarithm-transformed intake rate, the variables being bird size, prey size, whether the bird was an oystercatcher eating mussels or breeding. This four-variable equation predicted the asymptote of the functional response with good precision in $93 \%$ of cases.

(6) As well as predicting the asymptote of the functional response, the equations will enable research workers engaged in many areas of shorebird ecology and behaviour to estimate intake rate without the need for conventional time-consuming field studies. They can also be used to estimate intake rate in the many species for which it is not yet possible to measure intake rate in the field, usually because a small bird is eating small prey.

(7) The equations could provide a useful stimulus to studies of shorebird ecology and behaviour across a wide range of scientific and applied issues including individualbased modelling of shorebird populations, predator-prey interactions, foraging theory, the quality of feeding grounds (measured in terms of potential intake rate), the trade-off between consuming food and other factors that may affect fitness, such as the risk of being taken by a predator, and food-related reproductive success.

(8) Workers on other groups should, perhaps, be stimulated by these findings from shorebirds to try to establish similar equations for other vertebrate taxa.

\section{AGKNOWLEDGEMENTS}

We are very grateful to Rob Willows, Jonathon Jeschke and Herve Fritz for very helpful comments. We are also very grateful to Associated British Ports for financial support. The project was also funded by the Coast Bird Diversity project supported by the European Commission. J. Castilla and C. Pacheco acknowledge financial support given by Minera Escondida Limitada (Antofagasta Project) and CASEB-FONDAP, Project 1501-0001.

\section{REFERENGES}

Alerstam, T., Gudmundsson, G. A. \& Johannesson, K. (1992). Resources for long distance migration: intertidal exploitation of Littorina and Mytilus by knots Calidris canutus in Iceland. Oikos 65, 179-189.

Barnard, C.J. \& Thompson, D. B. A. (1985). Gulls and Plovers. Croom Helm, London, U.K.

Bennett, P. M. \& Owens, I. P. F. (2002). Evolutionary ecology of birds: life histories, mating systems and extinction. Oxford University Press, Oxford. 
Bergstrom, U. \& England, G. (2004). Spatial scale, heterogeneity and functional responses. Fournal of Animal Ecology 73, 487-493.

Blomert, A.-M., Engelmoer, M. \& Logemann, D. (1983). Voedseloecologie van de scholekster ophet Friese wad. Report Rijksdienst IJsselmeerpolders, Lelystad, The Netherlands.

Boates, J. S. \& Goss-Custard, J. D. (1989). Foraging behaviour of oystercatchers, Haematopus ostralegus, during a diet switch from worms Nereis diversicolor to clams Scrobicularia plana. Canadian Fournal of Zoology 67, 2225-2231.

Boates, J. S. \& Goss-Custard, J. D. (1992). Foraging behaviour of oystercatchers Haematopus ostralegus specialising on different species of prey. Canadian Fournal of Zoology 70, 2398-2404.

Brown, R. A. \& O’Connor, R. J. (1976). Some observations on the relationship between oystercatchers Haematopus ostralegus L. and cockles Cardium edule L. in Strangford Lough. Irish Naturalist 18, 73-80.

Bryant, D. M. \& Westerterp, K. R. (1980). Energetics of foraging and free existence in birds. Proceedings International Ornithological Congress 17, 292-299.

Bunskoeke, E.J. (1988). Over de fluctuaties van de prooikeus van de scholekster (Haematopus ostralegus) in het broedseizoen 1986 op Schiermonnikoog. Studentenrapport Zoologisch Laboratorium, Risjksuniversiteit Groningen.

Bunskoeke, E.J., Ens, B.J., Hulscher, J. B. \& De Vlas, S. J. (1996). Why do oystercatchers Haematopus ostralegus switch from feeding on Baltic tellin Macoma balthica to feeding on the ragworm Nereis diversicolor during the breeding season? Ardea $\mathbf{8 4 A}$, 91-104.

Cadman, M. D. (1980). Age-related foraging efficiency of the American oystercatcher (Haematopus palliatus). M.Sc. thesis, University of Toronto.

Caldow, R. W. G. \& Furness, R. W. (2001). Does Holling's disc equation explain the functional response of a kleptoparasite? Journal of Animal Ecology 70, 650-662.

Castro, M. (2001). Ecologia de la alimentacion en el Chorlitejo patinegro Charadrius alexandrinus: existe plasticidad comportamental y fisiolgica asociada al sexo? Tesis Doctoral, Universidad de Cadiz.

Cayford, J. T. \& Goss-Custard, J. D. (1990). Seasonal changes in the size selection of mussels, Mytilus edulis, by oystercatchers, Haematopus ostralegus: an optimality approach. Animal Behaviour 40, 609-624.

Cramp, S. \& Simmons, K. E. L. (1983). Handbook of the Birds of Europe and the Middle East and North Africa vol. 3: Waders to Gulls. Oxford University Press, Oxford.

Cresswell, W. (1994). Age-dependent choice of redshank (Tringa totanus) feeding location: profitability or risk? Fournal of Animal Ecology 63, 589-600.

Davidson, P. E. (1967). A study of the oystercatcher (Haematopus ostralegus L.) in relation to the fishery for cockles (Cardium edule L.) in the Burry Inlet, South Wales. Fisheries Investigation London (Series II) 25, 1-28.

Dekinga, A. \& Piersma, T. (1993). Reconstructing diet composition on the basis of faeces in a mollusc-eating wader, the knot Calidris canutus. Bird Study 40, 144-156.

Dierschke, V. (1993). Food and feeding ecology of purple sandpipers Calidris maritima on rocky intertidal habitats (Helgoland, German Bight). Netherlands Journal of Sea Research 31, 309-317.

Dierschke, V. (1998). High profit at high risk for juvenile dunlins Calidris alpina stopping over at Helgoland (German Bight). Ardea 86, 59-69.
Dierschke, V., Kube, J., Probst, J. \& Brenning, U. (1999). Feeding ecology of dunlins Calidris alpina staging in the southern Baltic Sea, 1. Habitat use and food selection. Fournal of Sea Research 42, 49-64.

Drinnan, R. E. (1957). The winter feeding of the oystercatcher (Haematopus ostralegus) on the edible cockle (Cardium edule). Fournal of Animal Ecology 26, 441-469.

Drinnan, R. E. (1958). The winter feeding of the oystercatcher (Haematopus ostralegus) on the edible mussel (Mytilus edulis) in the Conway estuary, North Wales. Fisheries Investigation London (Series II) $22,1-15$.

Durell, S. E. A., Goss-Gustard, J. D. \& Perez-Hurtado, A. (1996). The efficiency of juvenile oystercatchers feeding on ragworms Nereis diversicolor. Ardea 84A, 153-158.

DüsING, M. (1995). Aktivitäts- und Raumnutzungsmuster des Alpenstrandläufers (Calidris alpina) zur Zeit des Herbstzuges im ostfriesischen Wattenmeer. Unpublished diploma thesis, University Frankfurt.

EichHoRn, G. (2001). Zur Bedeutung der Steppenseen ZentralKasachstans als Rastplatz arktischer Watvögel Charadrii, insbesondere zur Rastplatzökologie von Zwergstrandläufer Calidris minuta und Odinshühnchen Phalaropus lobatus. Unpublished Diploma thesis, University Frankfurt.

Ens, B. J. \& Alting, D. (1996). The effect of an experimentally created mussel bed on bird densities and food intake of the oystercatcher Haematopus ostralegus. Ardea 84A, 493-507.

Ens, B. J., Bunskoeke, A. E. J., Hoekstra, R., Hulscher, J. B. \& De Vlas, S.J. (1996a). Prey choice and search speed: why simple optimality fails to explain the prey choice of oystercatchers Haematopus ostralegus feeding on Macoma balthica and Nereis diversicolor. Ardea 84A, 73-89.

Ens, B. J., Dirksen, S., Smit, C. J. \& Bunskoeke, A. E. J. (1996b). Seasonal changes in size selection and intake rate of oystercatchers Haematopus ostralegus feeding on the bivalves Mytilus edulis and Cerastoderma edule. Ardea 84A, 159-176.

Ens, B. J., Esselink, P. \& Zwarts, L. (1990). Kleptoparasitism as a problem of prey choice: a study on mudflat-feeding curlews, Numenius arquata. Animal Behaviour 39, 219-230.

Ens, B.J. \& Goss-Custard, J. D. (1984). Interference among oystercatchers, Haematopus ostralegus, feeding on mussels, Mytilus edulis, on the Exe estuary. Fournal of Animal Ecology 53, 217-231.

Ens, B.J., Klaassen, M. \& Zwarts, L. (1993). Flocking and feeding in the fiddler crab (Uca tangeri): prey availability as risk-taking behaviour. Netherlands Fournal of Sea Research 31, 477-494.

Ens, B. J., Merck, T., Smit, C. J. \& Bunskoeke, A. E. J. (1996c). Functional and numerical response of oystercatchers Haematopus ostralegus on shellfish populations. Ardea 84A, 441-452.

Felsenstein, J. (1985). Phylogenies and the comparative method. American Naturalist 125, 1-15.

Freckleton, R. P., Harvey, P. H. \& Pagel, M. (2002). Phylogenetic analysis and comparative data: a test and review of evidence. American Naturalist 160, 712-726.

Gill, J. A., Norris, K. \& Sutherland, W.J. (2001). Depletion models can predict shorebird distribution at different spatial scales. Proceedings of the Royal Society of London Series B 268, 369-376.

Goldstein, H. (2003). Multilevel statistical models. 3rd Edn. Hooder Arnold, London, UK.

Goss-Custard, J. D. (1966). The winter feeding ecology of the redshank (Tringa totanus L.) on the Ythan estuary, NE Scotland. Ph.D. thesis, University of Aberdeen. 
Goss-Custard, J. D. (1970). Factors affecting the diet and the feeding rate of the redshank, Tringa totanus. In: Animal Populations in Relation to their Food Resources (ed. A. Watson), pp. 101-110. Blackwells, Oxford.

Goss-Custard, J. D. (1996a). Optimal foraging and the size selection of worms by redshank, Tringa totanus, in the field. Animal Behaviour 25, 10-29.

Goss-Custard, J. D. (1977b). Predator responses and prey mortality in redshank, Tringa totanus (L.), and a preferred prey, Corophium volutator (Pallas). Foumal of Animal Ecology 46, 21-35.

Goss-Custard, J. D. (1977c). The ecology of the Wash. III. Density-related behaviour and the possible effects of a loss of feeding grounds on wading birds (Charadrii). Fournal of Applied Ecology 14, 721-739.

Goss-Gustard, J. D. $(1977 d)$. The energetics of prey selection by redshank, Tringa totanus (L.), in relation to prey density. Fournal of Animal Ecology 46, 1-19.

Goss-Custard, J. D. (1980). Competition for food and interference among waders. Ardea 68, 31-52.

Goss-Custard, J. D. (2003). Fitness, demographic rates and managing the coast for shorebird populations. Wader Study Group Bulletin 100, 183-191.

Goss-Custard, J. D., Clarke, R. T., McGrorty, S., Nagarajan, R., Sitters, H. P. \& West, A. D. (2002). Beware of these errors when measuring intake rates in waders. Wader Study Group Bulletin 98, 30-37.

Goss-Custard, J. D., Jenyon, R. A., Jones, R. E., Newbery, P. E. \& Williams, R., Le, B. (1977). The ecology of the Wash. II. Seasonal variation in the feeding conditions of wading birds (Charadrii). Journal of Applied Ecology 14, 701-719.

Goss-Custard, J. D. \& Rothery, P. (1976). A method for measuring some components of foraging of certain birds in the field. Animal Behaviour 24, 545-550.

Goss-Gustard, J. D. \& Stillman, R. A. (In Press). Individualbased models and the management of shorebird populations. Natural Resource Modeling.

Goss-Gustard, J. D., West, A. D., Stillman, R. A., Durell, S. E. A., Le, V. Dit, Caldow, R. W. C., McGrorty, S. \& Nagarajan, R. (2001). Density-dependent starvation in a vertebrate without significant depletion. Fournal of Animal Ecology 70, 955-965.

Gratto, G. W., Thomas, L. H. \& Gratto, C. L. (1984). Some aspects of the foraging ecology of migrant juvenile sandpipers in the outer Bay of Fundy. Canadian Journal of Zoology 62, 1889-1892.

Green, R. (1978). Factors affecting the diet of farmland skylarks, Alauda arvensis. Fournal of Animal Ecology 47, 913-928.

Grimm, V. \& RAILSBEck, S. F. (2005). Individual-based Modelling and Ecology. Princeton University Press, Princeton.

Habekotté, B. (1987). Scholeksters en Slijkgapers. Studentenrapport Zoologisch Laboratorium, Risjksuniversiteit Groningen.

Harvey, P. H. \& Pagel, M. (1991). Comparative methods in evolutionary biology. Oxford University Press, Oxford.

Harvey, P. H. \& Rambaut, A. (2000). Comparative methods for adaptive radiations. Philosophical Transactions of the Royal Society London B 355, 319-320.

Heppleston, P. B. (1971). The feeding ecology of oystercatchers (Haematopus ostralegus) in winter in northern Scotland. Fournal of Animal Ecology 40, 651-672.

Hiddink, J. G. (2003). Modelling the adaptive value of intertidal migration and nursery use in the bivalve Macoma balthica. Marine Ecology Progress Series 252, 173-185.
Hilgerloh, G. \& Pfeifer, D. (2002). Size selection and competition for mussels, Mytilus edulis, by oystercatchers, Haematopus ostralegus, herring gulls, Larus argentatus, and common eiders, Somateria mollissima. Ophelia 56, 43-54.

Hockey, P. A. R., Plaganyi, E. E., Turpie, J. K. \& Phillits, T. E. (1996). Foraging behaviour of crab plovers Dromas ardeola at Mida Creek, Kenya. Ostrich 67, 33-44.

Hockey, P. A. R., Turpie, J. K., Plaganyi, E. E. \& Phillips, T. E. (1999). Scaling patterns in the foraging behaviour of sympatric plovers: effects of body size and diet. Fournal of Avian Biology 30, $40-46$.

Hockey, P. A. R., Turpie, J. K. \& Velasquez, G. R. (1998). What selective pressures have driven the evolution of deferred northward migration by juvenile waders? Journal of Avian Biology 29, 325-330.

Holling, G. S. (1959). Some characteristics of simple types of predation and parasitism. The Canadian Entomologist 91, 385-398.

Hosper, U. G. (1978). Fourageerstrategie en voedselopname van Scholeksters (Haematopus ostralegus) in het binnenlend. Studentenrapport Zoologisch Laboratorium, Risjksuniversiteit Groningen.

Hughes, R. N. (1970). An energy budget for a tidal-flat population of the bivalve Scrobicularia plana (da Costa). Fournal of Animal Ecology 39, 357-381.

Hulscher, J. B. (1976). Localisation of cockles (Cardium edule L.) by the oystercatcher (Haematopus ostralegus L.) in darkness and daylight. Ardea 64, 292-310.

Hulscher, J. (1982). The oystercatcher as a predator of the bivalve, Macoma balthica, in the Dutch Wadden Sea. Ardea $\mathbf{7 0}$ 89-152.

Hulscher, J. B., Bunskoeke, E. J., Alting, D. \& Ens, B. J. (1996). Subtle differences between male and female oystercatchers Haematopus ostralegus in locating and handling the bivalve mollusc Macoma balthica. Ardea 84A, 117-130.

Jeschke, J. M., Kopp, M. \& Tollrian, R. (2002). Predator functional responses: discriminating between handling and digesting prey. Ecological Monographs 72, 95-112.

Jeschie, J. M., Kopp, M. \& Tollrian, R. (2004). Consumer-food systems: why type I functional responses are exclusive to filter feeders. Biological Reviews 79, 337-349.

Jeschke, J. M. \& Tollrian, R. (2005). Predicting herbivore feeding times. Ethology 111, 187-206.

Johnstone, I. \& Norris, K. (2000). Not all oystercatchers Haematopus ostralegus select the most profitable common cockles Cerastoderma edule: a difference between feeding methods. Ardea 88, 137-153.

Kalejta, B. (1992). Time budget and predatory impact at the Berg River estuary, South Africa. Ardea 80, 327-342.

Kalejta, B. (1993). Intense predation cannot always be detected experimentally: a case study of shorebird predation on Nereid polychaetes in South Africa. Netherlands Journal of Sea Research 31, 385-393.

Kalejta, B. \& Hockey, P. A. R. (1994). Distribution of shorebirds at the Berg River estuary, South Africa, in relation to foraging modes, food supply and environmental features. Ibis 136, 233-239.

Kersten, M. \& Piersma, T. (1984). Voedselkeuze en voedselopname van Zilverplevieren Pluvialis squatarola in de Waddenzee tijdens de voor-en najaarstrek. Limosa 57, 105-111.

Koene, P. (1978). De Scholekster: aantalseffecten op de voedselopname. Studentenrapport Zoologisch Laboratorium, Risjksuniversiteit Groningen. 
Krebs, J. R., Stephens, D. W. \& Sutherland, W. J. (1983). Optimal foraging. Perspectives in Ornithology, pp. 165-216. Cambridge University Press, Cambridge.

KRÜ GER, C. (1997). Untersuchungen zur Nahrungsökologie und Nahrungsstrategie im Ostseeraum rastender Kiebitzregenpfeifer (Pluvialis squatarola). Unpublished Diploma thesis, University Oldenburg.

Leopold, M. F., Swennen, C. \& De Bruijn, L. L. M. (1989). Experiments on selection of feeding site and food size in oystercatchers, Haematopus ostralegus, of different social status. Netherlands Journal of Sea Research 23, 333-346.

LifJeld, J. (1984). Prey selection in relation to body size and bill length of five species of waders feeding in the same habitat. Ormis Scandinavica 15, 217-226.

Maagard, L. \& Jensen, K. T. (1994). Prey size selection, intake rate and distribution of staging oystercatchers (Haematopus ostralegus) feeding on an intertidal mussel bed (Mytilus edulis). Ophelia Supplement 6, 210-215.

Martin, A. P. (1991). Feeding ecology of birds on the Swartkops Estuary, South Africa. Ph.D. thesis, University of Port Elizabeth.

Masero, J. A. (1998). Obtención de recursos tróficos por limícolas (Aves: Charadrii) en fangos intermareales y salinas adyacentes en el Parque Natural de la Bahía de Cádiz (SO España). Ph.D. thesis, Universidad de Cádiz.

Masero, J. A. (2002). Why don't Knots feed extensively on the crustacean Artemia? Bird Study 9, 304-306.

Masero, J. A. (2003). Assessing alternative anthropogenic habitat for conserving waterbirds: Salinas as buffer areas against the impact of natural habitat loss for shorebirds. Biodiversity and Conservation 12, 1157-1173.

Masero, J. A. \& Perez-Hurtado, A. (2001). Importance of the supratidal habitats for maintaining overwintering shorebird populations: how redshanks use tidal mudflats and adjacent saltworks in southern Europe. Condor 103, 21-30.

Meire, P. H. (1996a). Feeding behaviour of oystercatchers Haematopus ostralegus during a period of tidal manipulation. Ardea 84A, 509-524.

MeIRe, P. H. (1996b). Using optimal foraging theory to determine the density of mussels (Mytilus edulis) that can be harvested by hammering oystercatchers Haematopus ostralegus. Ardea $\mathbf{8 4 A}$, $141-152$.

Meire, P. H. \& Ervynck, A. (1986). Are oystercatchers (Haematopus ostralegus) selecting the most profitable mussels (Mytilis edulis)? Animal Behaviour 34, 1427-1435.

Mitchell, W. A. \& Brown, J. S. (1990). Density-dependent harvest rates by optimal foragers. Oikos 57, 180-190.

Moreira, F. (1994a). Diet and feeding rates of knots Calidris canutus in the Tagus estuary (Portugal). Ardea 82, 133-136.

MoreIra, F. (1994b). Diet, prey size selection and intake rates of black-tailed Godwits, Limosa limosa, feeding on mudflats. Ibis 136, 349-355.

Moreira, F. (1996). Diet and feeding behaviour of grey plovers Pluvialis squatarola and redshanks Tringa totanus in a Southern Europe estuary. Ardeola 43, 145-156.

MüLLER, M. (1999). Die nahrungsökologische Bedeutung von Schlickwatten für Wat- und Wasservögel im ostfriesischen Rückseitenwatt. Unpublished diploma thesis, University Bonn.

Nagarajan, R. (2000). The foraging behaviour of oystercatchers (Haematopus ostralegus) in relation to food depletion during winter on the River Exe estuary, England. Ph.D. thesis, University of Exeter.
NeHLs, G. (1992). Food selection of knots Calidris canutus in the Wadden Sea: the importance of seasonal and annual variation of food availability. Unpublished report.

Newman, M. C. (1993). Regression analysis of log transformed data: statistical bias and its correction. Environmental Toxicology and Chemistry 12, 1129-1131.

NorRIs, K. (1999). A trade-off between energy intake and exposure to parasites in oystercatchers feeding on a bivalve mollusc. Proceedings of the Royal Society of London Series B 266, 1703-1709.

Norris, K. \& Johnstone, I. (1998a). Interference competition and the functional response of oystercatchers searching for cockles by touch. Animal Behaviour 56, 639-650.

Norris, K. \& Johnstone, I. (1998b). The functional response of oystercatchers (Haematopus ostralegus) searching for cockles (Cerastoderma edule) by touch. Fournal of Animal Ecology 67, 329-346.

Pacheco, C. J. \& Castilla, J. C. (2000). Ecologia trofica de los ostreros Haematopus ostralegus pitanay (Murphy 1925) and Haematopus ater (Vieillot et Oudart 1825) on beds of the tunicate Pyura praeputialis (Heller 1878) in the Bay of Antofagasta, Chile. Revista Chilena de Historia Natural 73, 533-541.

PAgel, M. D. (1992). A method for the analysis of comparative data. Fournal of Theoretical Biology 156, 431-442.

Paton, T. A., Baker, A. J., Groth, J. G. \& Barrowclough, G. F. (2003). RAG-1 sequences resolve phylogenetic relationships within Charadriiform b. Molecular Phyllogeny and Evolution 29, 268-278.

Perez-Hurtado, A. (1992). Ecologia alimentaria de las aves Limicolas invernantes en la bahia de Cadiz (Orden Charadriiformes): distribucion y uso del habitat. Ph.D. thesis, University of Seville.

Petersen, B. (1995). Nahrungsökologische Bedeutung verschiedener Mischwattbereiche im ostfriesischen Wattenmeer für Watvögel und Möwen (Charadrïformes: Charadrii und Lari) während des Herbstzuges. Unpublished diploma thesis, University Marburg.

Pienkowski, M. W. (1982). Diet and energy intake of grey and ringed plovers, Pluvialis squatarola and Charadrius hiaticula, in the non-breeding season. Fournal of the Zoological Society of London 197, 511-549.

Piersma, T. $(1986 a)$. Eastern curlew Numenius madagascariensis feeding on Macrophtalmus japonicus and other ocypodid crabs in the Nakdong estuary, South Korea. Ети 86, 156-160.

Piersma, T. (1986b). Foraging behaviour of terek sandpipers Xenus cinereus feeding on sand-bubbling crabs Scopimera globosa. Fournal für Ornithologie 127, 475-486.

Piersma, T. (1991). Red knots in New Zealand eat molluscs too: preliminary diet observations at Miranda, Firth of Thames and Farewell Spit in November 1990. Stilt 19, 30-35.

Piersma, T., Hoekstra, R., Dekinga, A., Koolhaas, P., Wolf, P., Battley, P. \& Wiersma, P. (1993). Scale and intensity of intertidal habitat use by knots Calidris canutus in the western Wadden Sea in relation to food, friends and foes. Netherlands fournal of Sea Research 31, 331-357.

Prater, A. J. (1972). The ecology of Morecambe Bay. The food and feeding habits of knots (Calidris canutus L.) in Morecambe Bay. Fournal of Applied Ecology 9, 179-194.

PRICE, T. (1997). Correlated evolution and independent contrasts. Philosophical Transactions of the Royal Society London B 352, 519-529.

Purvis, A. \& Rambaut, A. (1995). Comparative analyses by independent contrasts: an Apple Macintosh application for analysing comparative data. Computer Applied Biosciences 11, 247-250. 
Rippe, H. \& Dierschke, V. (1997). Picking out the plum jobs: feeding ecology of curlews Numenius arquata in a Baltic Sea wind flat. Marine Ecology Progress Series 159, 239-247.

Scheiffarth, G. (2003). Born to fly-migratory strategies and stopover ecology in the European Wadden Sea of a longdistance migrant, the bar-tailed godwit (Limosa lapponica). Ph.D. Thesis, University of Oldenburg.

Shipley, L. A., Gross, J. E., Spalinger, D. E., Thompson Hobbs, N. \& Wunder, B. A. (1994). The scaling on intake rate in mammalian herbivores. American Naturalist 143, 1055-1082.

Siman, H. Y. (1989). Feeding ecology, movements and biogeographic origins of curlew Numenius arquata (L.) wintering on the Severn Estuary. Ph.D. thesis, University of Wales.

SitTers, H. P. (2000). The role of night-feeding in shorebirds in an estuarine environment with specific reference to mussel-feeding oystercatchers. D.Phil thesis, University of Oxford.

Smart, J. \& Gill, J. A. (2003). Non-intertidal habitat use by shorebirds: a reflection of inadequate intertidal resources? Biological Conservation 111, 359-369.

Smith, P. C. (1975). A study of the winter feeding ecology and behaviour of the bar-tailed godwit (Limosa lapponica). Ph.D. thesis, University of Durham.

Snijders, T. A. B. \& Bosker, R. J. (1999). Multilevel analysis: an introduction to basic and advanced multilevel modelling. SAGE Publications, London.

Speakman, J. R. (1987). Apparent absorption efficiencies for redshank (Tringa totanus L.) and oystercatcher (Haematopus ostralegus L.) - implications for the predictions of optimal foraging models. American Naturalist 130, 677-691.

Stillman, R. A., Goss-Custard, J. D. \& Galdow, R. W. G. (1997). Modelling interference from basic foraging behaviour. fournal Animal Ecology 66, 692-703.

Stillman, R. A., Poole, A. E., Goss-Custard, J. D., Caldow, R. W. G., Yates, M. G. \& Triplet, P. (2002). Predicting the strength of interference more quickly using behaviour-based models. Fournal of Animal Ecology 71, 532-541.

Sutherland, W.J. (1982a). Do oystercatchers select the most profitable cockles? Animal Behaviour 30, 857-861.

Sutherland, W.J. (1982b). Spatial variation in the predation of cockles by oystercatchers at Traeth Melynog, Anglesey. II. The pattern of mortality. Fournal of Animal Ecology 51, 491-500.

Swennen, C. (1990). Oystercatchers feeding on giant bloody cockles in the Banc d'Arguin. Ardea 78, 53-61.

Swennen, G., Leopold, M. F. \& De Bruijn, L. L. M. (1989). Timestressed oystercatchers, Haematopus ostralegus, can increase their intake rate. Animal Behaviour 38, 8-22.

Thomas, G. H., Wills, M. A. \& Székely, T. (2004). Phylogeny of the shorebirds, gulls and alcids (Aves: Charadrii) from the cyochrome- $b$ gene: parsimony, Bayesian inference, minimum evolution and quartet puzzling. Molecular Phyllogeny and Evolution 30, 516-526.

TriPLET, P. (1984). Facteurs abiotiques et biotiques conditionnant une stratégie de recherche de: l'example de l'huitrier-pie Haematopus ostralegus prédateur de la coque Cerastoderma edule en baie de Somme. Memoires DEA Ecologiques, Universitaire de Paris VI.

Triplet, P. (1989). Sélectivité alimentaire liée à l'age chez l'huîtrier-pie (Haematopus ostralegus) consommateur de Nereis diversicolor en baie de Somme. Gibier Fauna Sauvage 6, 427-436.

Triplet, P., Stillman, R. A. \& Goss-Custard, J. D. (1999). Prey abundance and the strength of interference in a foraging shorebird. Fournal of Animal Ecology 68, 254-265.
Tulp, I. H. \& De GoeIJ, P. (1994). Evaluating wader habitats in Roebuck Bay (north-western Australia) as a springboard for northbound migration in waders, with a focus on great knots. Ети 94, 78-95.

Turpie, J. K. \& Hockey, P. A. R. (1993). Comparative diurnal and nocturnal foraging behaviour and energy intake of premigratory grey plovers Pluvialis squatarola and whimbrels Numenius phaeopus in South Africa. Ibis 135, 156-165.

Turpie, J. K. \& Hockey, P. A. R. (1996). Foraging ecology and seasonal energy budgets of estuarine grey plovers Pluvialis squatarola and whimbrels Numenius phaeopus at the southern tip of Africa. Ardea 84, 57-74.

Turpie, J. K. \& Hockey, P. A. R. (1997). Adaptive variation in the foraging behaviour of grey plovers Pluvialis squatarola and whimbrels Numenius phaeopu. Ibis 139, 289-298.

UMLAND, J. (2000). Die nahrungsökologische Bedeutung einer Wattlebensgemeinschaft für Wat- und Wasservögel im ostfriesischen Wattenmeer. Unpublished diploma thesis, University Hamburg.

Van Der Meer, J., Piersma, T. \& Beukema, J. J. (2001). Population dynamics of benthic species on tidal flats: the possible roles of shorebird predation. Ecological Studies 151, 317-335.

Van Gils, J. A. \& Piersma, T. (2004). Digestively constrained predators evade the cost of interference competition. Fournal of Animal Ecology 73, 386-398.

Veenstra, J. (1977). Het fourageren van de scholekster in het binnenland. Studentenrapport Zoologisch Laboratorium, Risjksuniversiteit Groningen.

Velasquez, G. R. (1993). The ecology and management of waterbirds at commercial saltpans in South Africa. Ph.D. thesis, University of Cape Town.

Velasquez, G. R. \& Navarro, R. A. (1993). The influence of water depth and sediment type on the foraging behaviour of whimbrels. Fournal of Field Ornithology 64, 149-157.

WAHLS, S. \& Exo, K.-M. (1996). Kiebitzregenpfeifer (Pluvialis squatarola) im Wattenmeer - Zwischenstop im Schlaraffenland? Verhandlungen der Deutschen Zoologischen Gesellschaft 89, 316.

WANINK, J. H. \& ZwARTS, L. (1985). Does an optimally foraging oystercatcher obey the functional response? Oecologia 67, 98-106.

Whelan, C. J. \& Brown, J. S. (2005). Optimal foraging and gut constraints: reconciling two schools of thought. Oikos $\mathbf{1 1 0}$ $481-496$

WolfF, S. (2000). Nahrungsökologische Bedeutung von Mischwatten im ostfriesischen Rückseitenwatt für Larolimikolen. Unpublished diploma thesis, University Oldenburg.

Worrall, D. H. (1981). The feeding behaviour of dunlin Calidris alpina (L.). Ph.D. thesis, University of Wales.

Worrall, D. H. (1984). Diet of the Dunlin Calidris alpina in the Severn estuary. Bird Study 31, 203-212.

Yates, M. G., Stillman, R. A. \& Goss-Custard, J. D. (2000). Contrasting interference functions and foraging dispersion in two species of shorebirds Charadrii. Fournal of Animal Ecology 69, 314-322.

YI, J. Y., Yoo, J. C. \& Won, P. O. (1994). Foraging behaviour and energy intake of premigratory eastern curlew Numenius madagascariensis on Kanghwa Island, Korea. Korean Gournal of Ornithology 1, 1-13.

ZwarTs, L. (1985). The winter exploitation of fiddler crabs $U c a$ tangeri by waders in Guinea-Bissau. Ardea 73, 3-12.

ZwARTs, L. (1990). Increased prey availability drives premigration hyperphagia in whimbrels and allows them to leave the Banc d'Arguin, Mauritania, in time. Ardea 78, 279-300. 
Zwarts, L. \& Blomert, A.-M. (1992). Why knot Calidris canutus take medium-sized Macoma balthica when six prey species are available. Marine Ecology Progress Series 83, 113-128.

Zwarts, L. \& Blomert, A.-M. (1996). Daily metabolised energy intake of oystercatchers Haematopus ostralegus feeding on larvae of the crane fly Tipula paludosa. Ardea 84, 221-228.

Zwarts, L., Blomert, A.-M. \& Hupkes, R. (1990). Increase of feeding time in waders preparing for spring migration from the Banc d'Arguin, Mauritania. Ardea 78, 237-256.

Zwarts, L. \& Dirksen, S. (1990). Digestive bottleneck limits the increase in food intake of whimbrel preparing for spring migration from the Banc d'Arguin, Mauritania. Ardea 78, 257-278.

Zwarts, L. \& Drent, R. (1981). Prey depletion and the regulation of predator density: oystercatchers (Haematopus ostralegus) feeding on mussels (Mytilus edulis). In Feeding and survival strategies of estuarine organisms (eds. N. V. Jones and W. J. Wolff), pp. 193-216. Plenum Press, New York.
Zwarts, L. \& Eselink, P. (1989). Versatility of male curlews (Numeniius arquata) preying upon Nereis diversicolor: deploying contrasting capture modes dependent on prey availability. Marine Ecology Progress Series 56, 255-269.

Zwarts, L. \& WANInK, J. H. (1984). How oystercatchers and curlews successively deplete clams In Coastal waders and wildfowl in winter (eds. P. R. Evans, J. D. Goss-Custard and W. G. Hale) pp. 69-83. Cambridge University Press, Cambridge.

Zwarts, L. \& WaninK, J. H. (1993). How the food supply harvestable by waders in the Wadden Sea depends on the variation in energy density, body weight, biomass, burying depth and behaviour of tidal-flat invertebrates. Netherlands Fournal of Sea Research 31, 441-476.

Zwarts, L., Ens, B. J., Goss-Gustard, J. D., Hulscher, J. B. \& Durell, S. E. A. LE V. Dit. (1996). Causes of variation in prey profitability and its consequences for the intake rate of the Oystercatchers Haematopus ostralegus. Ardea 84, 229-268.

\section{APPENDIX 1. ESTIMATING THE MEAN ASH-FREE DRY MASS OF PREY GONSUMED BY SHOREBIRDS}

In order to apply the equations to predict either the asymptote or half-asymptote constant of the functional response, it is necessary to know the mean ash-free dry mass (AFDM) of the prey that the birds are eating. There are a variety of methods for estimating the mean mass of consumed prey in the field (Goss-Custard et al., 2002) but they are almost always very time-consuming. Furthermore, behaviour-based models of shorebird foraging require the size of prey taken by the birds to be continually updated in the model as depletion by the birds themselves and other mortality agents change not only the abundance of the prey but also their average mass. Although in principle it should be possible to use foraging theory to predict prey size in any circumstance, in practise this is again very time-consuming, even in the limited number of species where the often immense practical difficulties can be resolved [redshank Tringa tetanus eating polychaete worms (Goss-Custard, 1977a); oystercatchers Haematopus ostralegus eating shellfish (Sutherland, 1982a; Wanink \& Zwarts, 1985; Meire \& Ervynck, 1986; Cayford \& Goss-Custard, 1990; Ens et al., $1996 a, b$; Norris \& Johnstone, 1998b)]. A simpler and more widely applicable method was therefore required.

The first step was to decide the size range from which each of the main shorebird species obtained most of its consumption. This was done by reviewing all the published and unpublished studies in which the length-frequency distribution of consumed prey had been recorded. The number of cases available for each species is shown in Table A1. On the basis of this review, the upper and lower lengths of prey from which each shorebird species obtained most (circa $95 \%$ ) of its consumption was gauged by eye, and are shown in Table A2.

The second step was to compare the mean AFDM of prey consumed within these size ranges with the mean AFDM of the prey in the sediment within these size ranges. Across all the available data, there was, as expected, a reasonably close correspondence $\left(R^{2}=95.4 \%, P<0.001\right)$ between the size taken and the size present (Fig. Al). This comparison was expressed in each case as the ratio of the AFDM of consumed prey to the AFDM of the prey in the substratum: the distribution of these ratios is shown in Fig. A2. Apart from three outlying points, the ratios follow a normal distribution.

A step-down multiple regression analysis of the variation in this ratio (excluding the three outliers) was conducted using the following independent variables: body mass of the birds, mean AFDM of the prey present in the sediment, whether or not the bird was an oystercatcher eating shellfish, whether prey were detected visually or by touch or was a polychaete or mollusc or crustacean or insect. This analysis identified only one significant correlate of this ratio: whether the prey was a crustacean. However, there were only 10 cases of crustacean prey out of a total sample of 227, and the absolute size of the difference was not large as the mean for crustacean prey was 1.1 whereas for all the other cases it was 1.05. For that reason, and for simplicity, the mean ratio across all data (excluding the three outliers) was calculated. The mean \pm S.E.M. was $1.048 \pm 0.021$ which was significantly different from both $0(P=<0.05)$ and from $1.1(P=<0.02)$. As a rough approximation, therefore, the results suggest that, in order to estimate the mean AFDM of the prey consumed by a shorebird in any situation (whether in a behaviour-based model or in a real situation), it is only necessary to multiply by 1.05 the mean AFDM of the prey in the sediment that fall within the size range consumed by the bird in question, as shown in Table A2.

The ratio 1.05 partly reflects the choice of upper and lower limit, of course. But it may also arise because large prey could be more detectable and/or profitable than smaller ones. Whatever the reason, this ratio provides a very simple way of predicting the mean AFDM of the prey consumed by shorebirds from the mean AFDM of those present in the sediment without the need to carry out extensive fieldwork. 
Table A1. The sources of data for determining the size range of the prey taken by shorebirds and the ratio between the mean ash-free dry mass of the prey taken and of those in the sediment. N1: sample sizes for the size ranges taken by the common NW European species of shorebirds given in Table A2. N2: the number of cases worldwide for establishing the ratio of the prey mass taken to the prey mass of the prey present. The value in parentheses in the European oystercatcher refers to the number of samples where the birds were eating either mussels or cockles.

\begin{tabular}{|c|c|c|c|c|}
\hline Species & & N1 & N2 & Sources of unpublished data \\
\hline $\begin{array}{l}\text { European } \\
\text { oystercatcher }\end{array}$ & Haematopus ostralegus & $82(50)$ & $123(88)$ & $\begin{array}{l}\text { J. D. Goss-Custard \& A. D. West; } \\
\text { R. Nagarajan; A. Perez-Hurtado; } \\
\text { H. Sitters; M. G. Yates }\end{array}$ \\
\hline
\end{tabular}
Sources of published data

\begin{tabular}{|c|c|c|c|c|c|}
\hline Ringed plover & Charadrius hiaticula & 9 & 1 & & Lifjeld (1984) \\
\hline Kentish plover & Charadrius alexandrinus & 6 & 6 & M. Castro & Castro (2001) \\
\hline Grey plover & Pluvialis squatarola & 9 & 6 & J. D. Goss-Custard \& A. D. West & $\begin{array}{l}\text { Dierschke et al. (1999), Kalejta (1993), Martin (1991), } \\
\text { Moreira (1996) }\end{array}$ \\
\hline Great knot & Calidris tenuirostris & - & 1 & & Tulp \& de Goeij (1994) \\
\hline Knot & Calidris canutus & 39 & 16 & & $\begin{array}{l}\text { Alerstam et al. (1992), Dekinga \& Piersma (1993), Goss-Custard } \\
\text { et al. (1977), Moreira (1994a), Piersma (1991), Piersma et al. (1993), } \\
\text { Nehls (1992), Prater (1972), Masero (2002), Zwarts \& Blomert } \\
\text { (1992) }\end{array}$ \\
\hline $\begin{array}{l}\text { Semipalmated } \\
\text { sandpiper }\end{array}$ & Calidris pusilla & - & 1 & & Gratto et al. (1984) \\
\hline Least sandpiper & Calidris minutilla & - & 1 & & Gratto et al. (1984) \\
\hline Curlew sandpiper & Calidris ferruginea & 6 & 2 & & Kalejta (1993), Lifjeld (1984), Masero (2003) \\
\hline Dunlin & Calidris alpina & 26 & 33 & & $\begin{array}{l}\text { Dierschke (1998), Dierschke } \text { et al. (1999), Goss-Custard et al. (1977), } \\
\text { Lifjeld (1984), Masero (2003), Worrall (1981, 1984) }\end{array}$ \\
\hline Ruff & Philomachus pugnax & 0 & 2 & & Lifjeld (1984) \\
\hline Black-tailed godwit & Limosa limosa & 4 & 4 & J. D. Goss-Custard \& A. D. West & Moreira $(1994 b)$ \\
\hline Bar-tailed godwit & Limosa lapponica & 5 & 0 & & Goss-Custard et al. (1977), Smith (1975) \\
\hline Whimbrel & Numenius phaeopus & 3 & 3 & & $\begin{array}{l}\text { Martin (1991), Velasquez \& Navarro (1993), Zwarts (1990), Zwarts } \\
\text { \& Dirksen (1990) }\end{array}$ \\
\hline Curlew & Numenius arquata & 28 & 18 & J. D. Goss-Custard \& A. D. West & $\begin{array}{l}\text { Ens et al. (1990), Goss-Custard et al. (1977), Rippe \& Dierschke } \\
\text { (1997), Zwarts \& Dirksen (1990), Zwarts \& Eselink (1989), Zwarts } \\
\text { \& Wanink (1984) }\end{array}$ \\
\hline Eastern curlew & Numenius madagascariensis & - & 1 & & Piersma $(1986 a)$ \\
\hline Redshank & Tringa totanus & 14 & 8 & & $\begin{array}{l}\text { Goss-Custard (1966; } 1977 a, b, d) \text {, Masero \& Perez-Hurtado (2001), } \\
\text { Moreira (1996), Perez-Hurtado (1992) }\end{array}$ \\
\hline Terek sandpiper & Xenus cinereus & - & 1 & & Piersma $(1986 b)$ \\
\hline
\end{tabular}

Brown \& O’Connor (1976), Cayford \& Goss-Custard (1990),

Davidson (1967), Drinnan (1957, 1958), Durell et al. (1996),

Ens \& Alting (1996), Goss-Custard et al. (1977), Habekotté (1987),

Hilgerloh \& Pfeifer (2002), Hughes (1970), Hulscher (1976),

Johnstone \& Norris (2000), Maagard \& Jensen (1994),

Meire (1996 a,b), Meire \& Ervynck (1986), Nagarajan (2000),

Sitters (2000), Sutherland (1982a), Swennen (1990),

Triplet (1984, 1989), Zwarts \& Wanink (1984), Zwarts et al. (1996)

Lifjeld (1984)

Dierschke et al.(1999), Kalejta (1993), Martin (1991),

Moreira (1996)

Tulp \& de Goeij (1994)

warts \& Blomert

Dierschke (1998), Dierschke et al. (1999), Goss-Custard et al. (1977),

Lifjeld (1984)

Moreira $(19946)$

Martin (1991), Velasquez \& Navarro (1993), Zwarts (1990), Zwarts

\& Wanink $(1984)$

Goss-Custard (1966; $1977 a, b, d)$, Masero \& Perez-Hurtado (2001),

Piersma $(1986 b)$ 
Table A2. The size range of prey from which the common shorebirds obtained most of their consumption across the studies listed in Table A1. Values are minimum and maximum $1 \mathrm{~mm}$ size classes, 1-29 means 1.000-29.999 mm long. 'max' means the birds take sizes up to the maximum length present in the sediment.

\begin{tabular}{|c|c|c|c|c|c|c|c|c|c|c|c|}
\hline & Mytilus & Mya & Cerastoderma & Scrobicularia & Macoma & Hydrobia & Corophium & Hediste* & Arenicola & Carcinus & Crangon \\
\hline Bar-tailed godwit & - & - & - & $8-19$ & $8-19$ & - & - & $25-\max$ & $25-\max$ & - & - \\
\hline Black-tailed godwit & - & - & - & $8-19$ & $8-19$ & - & - & $25-\max$ & - & - & 4-max \\
\hline Curlew & - & $25-\max$ & $8-19$ & $20-49$ & 8-max & - & - & $50-\max$ & $50-\max$ & $10-39$ & - \\
\hline $\begin{array}{l}\text { Gurlew sandpiper/ } \\
\text { dunlin }\end{array}$ & - & - & - & $3-6$ & $3-6$ & $1-4$ & 3-max & $10-59$ & - & - & - \\
\hline Grey plover & - & - & - & $8-19$ & $8-19$ & $1-4$ & - & $20-\max$ & $20-\max$ & - & - \\
\hline Knot & $5-24$ & $8-16$ & $5-14$ & $8-16$ & $8-16$ & $1-4$ & - & $10-59$ & - & - & - \\
\hline Oystercatcher & $30-59$ & $16-39$ & $15-\max$ & $20-\max$ & $12-\max$ & - & - & 0-99.9 & $50-\max$ & $10-50$ & - \\
\hline Redshank & - & $7-13$ & - & $7-13$ & $7-13$ & $1-4$ & 4-max & $15-79$ & - & $3-7$ & 4-max \\
\hline $\begin{array}{l}\text { Ringed/Kentish } \\
\text { plover }\end{array}$ & - & - & - & - & - & $1-4$ & 3-max & $10-49$ & - & - & - \\
\hline
\end{tabular}

* = and other worms too, such as Lanice, Cirratulids etc.

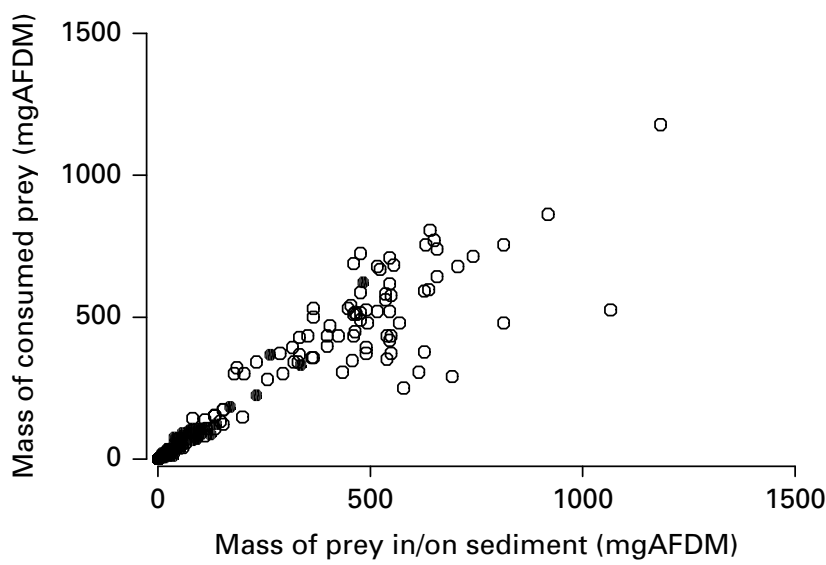

Fig. A1. The mean ash-free dry mass (AFDM) of the prey consumed by shorebirds in relation the mean ash-free dry mass of the prey in or on the sediment where they were feeding. Open circles show European oystercatchers eating either mussels or cockles. Filled circles show European oystercatchers eating other prey species and the data from all other shorebird species.

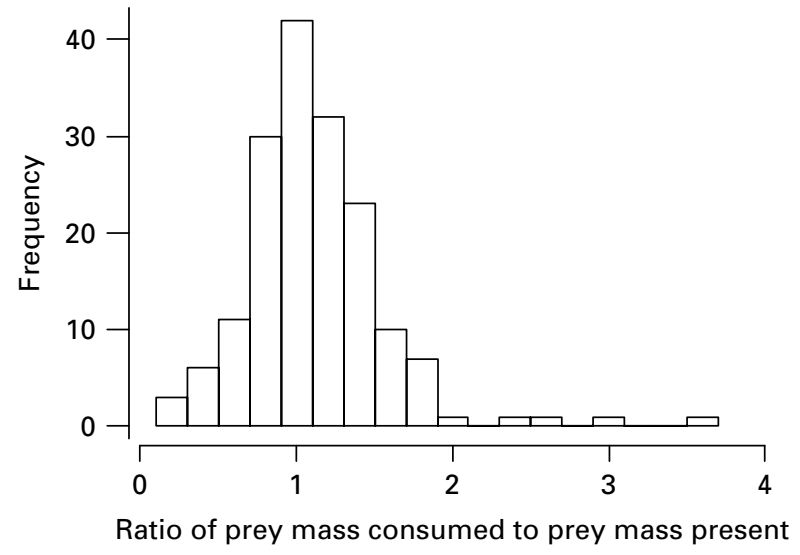

Fig. A2. Frequency histogram of the ratios of the mean ashfree dry mass (AFDM) of the prey consumed by shorebirds and the mean AFDM of the prey within the appropriate size range present in the sediment. 


\section{APPENDIX 2. RESULTS OF ADDING FIXED EFFEGTS TO GENERALISED LINEAR MIXED MODELS (GLMMS) OF LOGE INTAKE RATE}

The first three columns of results illustrate the parameter estimates from a generalised linear model (GLM) of the same data, whilst the second three provide our estimates from the GLMM. The third three provides the parameter estimates from fitting the two-variable model given in Table 5, but in this instance run as a GLMM. Note that non-significant terms for the models are not given (but see Table 5).

\begin{tabular}{|c|c|c|c|c|c|c|c|c|c|c|}
\hline \multirow[b]{2}{*}{ Fixed Effect } & \multirow[b]{2}{*}{$\mathrm{df}$} & \multicolumn{3}{|c|}{ GLM all data } & \multicolumn{3}{|c|}{ GLMM all data } & \multicolumn{3}{|c|}{ GLMM 2 FE model } \\
\hline & & $\begin{array}{l}\text { Parameter } \\
\text { estimate }\end{array}$ & $\begin{array}{l}\text { Standard } \\
\text { error }\end{array}$ & $\begin{array}{l}\text { Wald } \\
\chi^{2}\end{array}$ & $\begin{array}{l}\text { Parameter } \\
\text { estimate }\end{array}$ & $\begin{array}{l}\text { Standard } \\
\text { error }\end{array}$ & $\begin{array}{l}\text { Wald } \\
\chi^{2}\end{array}$ & $\begin{array}{l}\text { Param. } \\
\text { estimate }\end{array}$ & $\begin{array}{l}\text { Standard } \\
\text { error }\end{array}$ & $\begin{array}{l}\text { Wald } \\
\chi^{2}\end{array}$ \\
\hline Intercept & 1 & -2.464 & 0.232 & 112.9 & -2.481 & 0.407 & 37.157 & -2.867 & 0.405 & 50.011 \\
\hline $\log _{e} B M$ & 1 & 0.168 & 0.051 & 10.982 & 0.170 & 0.087 & 3.839 & 0.273 & 0.085 & 10.369 \\
\hline $\log _{\mathrm{e}} \mathrm{PM}$ & 1 & 0.116 & 0.092 & 1.585 & 0.083 & 0.108 & 0.598 & 0.337 & 0.019 & 313.3 \\
\hline $\log _{e} B M \times \log _{e} P M$ & 3 & 0.057 & 0.016 & 12.404 & 0.065 & 0.019 & 11.823 & $\mathrm{~N} / \mathrm{A}$ & $\mathrm{N} / \mathrm{A}$ & $\mathrm{N} / \mathrm{A}$ \\
\hline Prey type & 3 & - & - & 56.853 & - & - & 41.512 & N/A & $\mathrm{N} / \mathrm{A}$ & $\mathrm{N} / \mathrm{A}$ \\
\hline Breeding & 1 & 0.425 & 0.074 & 33.247 & 0.440 & 0.070 & 39.079 & $\mathrm{~N} / \mathrm{A}$ & $\mathrm{N} / \mathrm{A}$ & $\mathrm{N} / \mathrm{A}$ \\
\hline Oyc. & 1 & -0.197 & 0.079 & 6.239 & -0.526 & 0.189 & 7.748 & $\mathrm{~N} / \mathrm{A}$ & $\mathrm{N} / \mathrm{A}$ & $\mathrm{N} / \mathrm{A}$ \\
\hline Mussel Oyc. & 1 & -0.328 & 0.072 & 20.805 & -0.374 & 0.069 & 29.049 & $\mathrm{~N} / \mathrm{A}$ & $\mathrm{N} / \mathrm{A}$ & $\mathrm{N} / \mathrm{A}$ \\
\hline
\end{tabular}

BM, body mass; PM, prey mass; Oyc, oystercatcher; Mussel Oyc, oystercatcher eating mussels. 